\title{
Differential effects of cisplatin on cybrid cells with varying mitochondrial DNA haplogroups
}

\author{
Sina Abedi ${ }^{\text {Corresp., }}{ }^{1}$, Gregory Yung ${ }^{1}$, Shari R Atilano ${ }^{1}$, Kunal Thaker ${ }^{1}$, Steven Chang ${ }^{1}$, Marilyn Chwa ${ }^{1}$, Kevin \\ Schneider $^{1}$, Nitin Udar ${ }^{1}$, Daniela Bota ${ }^{2}$, M Cristina Kenney ${ }^{\text {Corresp. }{ }^{1,3}}$ \\ ${ }^{1}$ Gavin Herbert Eye Institute, University of California, Irvine, Irvine, CA, United States \\ Department of Neurology, Neuro-Oncology Division, University of California, Irvine, Irvine, CA, United States \\ 3 Department of Pathology and Laboratory Medicine, University of California, Irvine, Irvine, CA, United States \\ Corresponding Authors: Sina Abedi, M Cristina Kenney \\ Email address: sabedi1@uci.edu, mkenney@hs.uci.edu
}

Background. Drug therapy yields different results depending on its recipient population. Cisplatin, a commonly used chemotherapeutic agent, causes different levels of resistance and side effects for different patients, but the mechanism(s) are presently unknown. It has been assumed that this variation is a consequence of differences in nuclear (n) DNA, epigenetics, or some external factor(s). There is accumulating evidence that an individual's mitochondrial $(\mathrm{mt})$ DNA may play a role in their response to medications. Variations within mtDNA can be observed, and an individual's mtDNA can be categorized into haplogroups that are defined by accumulations of single nucleotide polymorphisms (SNPs) representing different ethnic populations.

Methods. The present study was conducted on transmitochondrial cytoplasmic hybrids (cybrids) that possess different maternal-origin haplogroup mtDNA from African (L), Hispanic [A+B], or Asian (D) backgrounds. Cybrids were created by fusing Rho0 ARPE-19 cells (lacking mtDNA) with platelets, which contain numerous mitochondria but no nuclei. These cybrid cells were cultured to passage five, treated with cisplatin, incubated for $48 \mathrm{~h}$, then analyzed for cell metabolic activity (tetrazolium dye (MTT) assay), mitochondrial membrane potential (JC-1 assay), cytotoxicity (lactate dehydrogenase (LDH) assay), and gene expression levels for $A L K, B R C A 1, E G F R$, and ERBB2/HER2.

Results. Results indicated that untreated cybrids with varying mtDNA haplogroups had similar relative metabolic activity before cisplatin treatment. When treated with cisplatin, (1) the decline in metabolic activity was greatest in $L(27.4 \%, p<0.012)>D(24.86 \%, p=0.0001)$ and $[A+B]$ cybrids $(24.67 \%, p=$ 0.0285 ) compared to untreated cybrids; (2) mitochondrial membrane potential remained unchanged in all cybrids (3) LDH production varied between cybrids $(L>[A+B], p=0.0270)$. (4) The expression levels decreased for $A L K$ in $L(p<0.0001)$ and $[A+B](p=0.0001)$ cybrids but not in $D$ cybrids $(p=0.285)$; and decreased for $E G F R$ in $[A+B]$ cybrids $(p=0.0246)$ compared to untreated hybrids.

Conclusion. Our findings suggest that an individual's mtDNA background may be associated with variations in their response to cisplatin treatment, thereby affecting the efficiency and the severity of side effects from the treatment. 


\section{Differential effects of cisplatin on cybrid cells with}

3 varying mitochondrial DNA haplogroups

Sina Abedi ${ }^{1}$, Gregory Yung ${ }^{1}$, Shari R. Atilano ${ }^{1}$, Kunal Thaker ${ }^{1}$, Steven Chang ${ }^{1}$, Marilyn Chwa ${ }^{1}$, Kevin Schneider ${ }^{1}$, Nitin Udar ${ }^{1}$, Daniela Bota ${ }^{2}$, M. Cristina Kenney ${ }^{1,3}$

${ }^{1}$ Gavin Herbert Eye Institute, University of California Irvine, Irvine, CA, USA

${ }^{2}$ Department of Neurology, Neuro-Oncology Division, University of California Irvine, Irvine, CA, USA 


\section{Abstract}

42 Background. Drug therapy yields different results depending on its recipient population.

43 Cisplatin, a commonly used chemotherapeutic agent, causes different levels of resistance and

44 side effects for different patients, but the mechanism(s) are presently unknown. It has been

45

46

47

48

49

50

51

52

53

54

55

56

57

58

59

60

61

62

63

64

65

66

67

68

69

70

\section{1}

72

73

74

75

76

77

78

79

80

assumed that this variation is a consequence of differences in nuclear (n) DNA, epigenetics, or some external factor(s). There is accumulating evidence that an individual's mitochondrial (mt) DNA may play a role in their response to medications. Variations within mtDNA can be observed, and an individual's mtDNA can be categorized into haplogroups that are defined by accumulations of single nucleotide polymorphisms (SNPs) representing different ethnic populations.

Methods. The present study was conducted on transmitochondrial cytoplasmic hybrids (cybrids) that possess different maternal-origin haplogroup mtDNA from African (L), Hispanic [A+B], or Asian (D) backgrounds. Cybrids were created by fusing Rho0 ARPE-19 cells (lacking mtDNA) with platelets, which contain numerous mitochondria but no nuclei. These cybrid cells were cultured to passage five, treated with cisplatin, incubated for $48 \mathrm{~h}$, then analyzed for cell metabolic activity (tetrazolium dye (MTT) assay), mitochondrial membrane potential (JC-1 assay), cytotoxicity (lactate dehydrogenase (LDH) assay), and gene expression levels for $A L K$, BRCA1, EGFR, and ERBB2/HER2.

Results. Results indicated that untreated cybrids with varying mtDNA haplogroups had similar relative metabolic activity before cisplatin treatment. When treated with cisplatin, (1) the decline in metabolic activity was greatest in L $(27.4 \%, \mathrm{p}<0.012)>\mathrm{D}(24.86 \%, \mathrm{p}=0.0001)$ and $[\mathrm{A}+\mathrm{B}]$ cybrids $(24.67 \%, \mathrm{p}=0.0285)$ compared to untreated cybrids; (2) mitochondrial membrane potential remained unchanged in all cybrids (3) LDH production varied between cybrids ( $\mathrm{L}>$ $[\mathrm{A}+\mathrm{B}], \mathrm{p}=0.0270)$. (4) The expression levels decreased for $A L K$ in $\mathrm{L}(\mathrm{p}<0.0001)$ and $[\mathrm{A}+\mathrm{B}](\mathrm{p}$ $=0.0001)$ cybrids but not in D cybrids $(\mathrm{p}=0.285)$; and decreased for $E G F R$ in $[\mathrm{A}+\mathrm{B}]$ cybrids $(\mathrm{p}$ $=0.0246)$ compared to untreated cybrids.

Conclusion. Our findings suggest that an individual's mtDNA background may be associated with variations in their response to cisplatin treatment, thereby affecting the efficiency and the severity of side effects from the treatment.

\section{Introduction}

Cisplatin is a platinum complex used in the chemotherapeutic treatments of various cancers, including ovarian and testicular cancers. It functions primarily by forming intrastrand crosslink adducts with the cell's DNA. This activates signal transduction pathways that disrupt transcription and replication, therefore inducing apoptosis in target cells (Dasari \& Tchounwou 2014; Florea \& Büsselberg 2011; Meijera et al. 2001; Siddik 2003). Side effects of cisplatin treatment include nausea, vomiting, hearing loss, myelosuppression, neurotoxicity, nephrotoxicity, hepatotoxicity, and cardiotoxicity (Dasari \& Tchounwou 2014). Unfortunately, cisplatin resistance is common, and the biochemical mechanisms leading to resistance are only partially understood (Amable 2016; Boulikas \& Vougiouka 2004; Cocetta et al. 2019; Damia \&

Peer] reviewing PDF | (2020:02:45720:2:0:NEW 13 Aug 2020) 
81 Broggini 2019; Florea \& Büsselberg 2011; Gottesman et al. 2016; Siddik 2003). Studies have 82 shown that mechanisms related to DNA repair, decreased drug uptake, or decreased DNA adduct 83 formation have been associated with increased cisplatin resistance (Amable 2016; Damia \& 84 Broggini 2019; Siddik 2003).

85

86

87

88

89

90

91

92

93

94

95

96

97

98

99

100

101

102

103

104

105

106

107

108

109

110

111

112

113

114

115

116

117

118

119

120

Variations in chemosensitivity to cisplatin have been observed in individuals of varying ethnic backgrounds (Jing et al. 2014; Kenney et al. 2014b; O'Donnell \& Dolan 2009; Tan et al. 2016; Yasuda et al. 2008). In a study investigating genetic biomarkers, Caucasian individuals demonstrated significantly greater susceptibility to identical doses of cisplatin compared to Asian individuals with late-stage non-small lung cancer (NSCLC) (Rose et al. 2014). O'Donnell et al. found that individuals of Asian descent (excluding India) were more susceptible to chemotherapy agents than individuals of European descent, and additionally, individuals of African descent showed greater resistance to anticancer treatments than those of European descent (O'Donnell \& Dolan 2009). These differences have previously been attributed to differences within the nuclear DNA and epigenetic factors (Amable 2016; Ha et al. 2018; Housman et al. 2014; O'Byrne et al. 2011; Siddik 2003; Stewart 2007; Ziliak et al. 2012).

Currently, evidence demonstrates that the mitochondria may also affect an individual's response to cisplatin treatment (Han et al. 2017; Marrache et al. 2014; Marullo et al. 2013; Tsuyoshi et al. 2017). Mitochondria are organelles that play an important role in ATP production, calcium homeostasis, cell signaling, and apoptosis. Previous studies have indicated that cisplatin treatment results in mitochondrial damage leading to reduced energy production and increased apoptotic activity (Devarajan et al. 2002; Han et al. 2017; Park et al. 2002; Patel et al. 2019; Tsuyoshi et al. 2017; Yáñez et al. 2003). Mitochondria are unique in that they contain their own DNA. Mitochondrial (mt) DNA is maternally inherited and can be categorized into haplogroups that are defined by single nucleotide polymorphism (SNP) variants. Different mtDNA haplogroups are used to classify populations of different maternal ancestral origins (www.mitomap.org/foswiki/pub/MITOMAP/MitomapFigures/WorldMigrations2012.pdf). Over the span of thousands of years, the different ancestral populations have accumulated distinct patterns of SNP variants within the mitochondrial genome, and it is likely that these SNP variants contribute to changes in cellular functions (Atilano et al. 2015; Jing et al. 2014; Kenney et al. 2014a; Kenney et al. 2014b; Kenney et al. 2013; Marrache et al. 2014; O'Donnell \& Dolan 2009; Patel et al. 2019; Penta et al. 2001; Singh et al. 1999; Tan et al. 2016; van Gisbergen et al. 2015).

Damage to the mtDNA accumulates because mitochondria, unlike the nucleus, lack efficient DNA repair mechanisms. Germline and somatic mutations, as well as copy number differences within the mtDNA, are associated with increased cancer risk. These mutations are likely to remain within the genome and be passed on to offspring (van Gisbergen et al. 2015). Cisplatin susceptibility within the mitochondria could, however, be lessened. Variations within the

Peer) reviewing PDF | (2020:02:45720:2:0:NEW 13 Aug 2020) 
121 mtDNA that prevent cisplatin from affecting ATP production, altering signaling pathways, or 122 forming DNA adducts could lead to cisplatin resistance (Czarnecka \& Bartnik 2011; Florea \& 123 Büsselberg 2011; Jarrett et al. 2008; Kenney et al. 2014b; Kenney et al. 2013; Singh et al. 1999).

124

125

126

127

128

129

130

131

132

133

134

135

136

137

138

139

140

141

142

143

144

145

146

147

148

149

150

151

152

153

154

155

156

157

158

159

160

Similarly, in a study on pancreatic cancer cells, Mizutani et al. demonstrated that mutations within the mitochondrial genome could result in cell resistance to cisplatin (Mizutani et al. 2009).

In order to study the effect(s) of differing mtDNA variants on drug susceptibility, the cybrid model can be used. Cybrids are transmitochondrial cell lines that contain identical nuclei, but mtDNA from different patients. These cybrids vary only in their mtDNA; therefore, differences in cellular function(s) between cybrids of varying mtDNA haplogroups can be attributed to their different mtDNA. Previously published data within our laboratory illustrated that transmitochondrial cybrids with mitochondria from either mtDNA haplogroup H (Southern Europe) or J (Northern Europe), exhibited varying levels of cellular metabolism, cell viability, and gene expression levels in vitro. J mtDNA haplogroup cybrids showed metabolism levels similar to those of cancer cells, as defined by the Warburg Phenomenon (Kenney et al. 2014a; Kenney et al. 2013; Patel et al. 2019).

We designed the present study to observe the effect(s) that mtDNA from L (African maternal descent), $[\mathrm{A}+\mathrm{B}]$ (Hispanic maternal descent), and $\mathrm{D}$ (Asian maternal descent) haplogroups have on cellular function(s) after cisplatin treatment. Our findings demonstrated that treating cybrids containing varying mtDNA haplogroups with cisplatin yielded differing levels of cellular metabolic activity, cytotoxicity, and gene expression. These findings support the hypothesis that mtDNA representing different racial/ethnic groups likely plays a role in the effectiveness and side effects induced by cisplatin.

\section{Materials \& Methods}

\section{Creation of Cybrid Cells}

Cytoplasmic hybrids (cybrids), cell lines with identical nuclear genomes but different mitochondrial genomes, were created and used in the fifth passage for all experiments. All experiments were carried out in accordance with the Institutional Review Board at the University of California, Irvine, (IRB \#2003-3131) and were consistent with Federal guidelines. Cybrid cells were created using platelets isolated from peripheral blood that was fused with Rho0 (mtDNA free) ARPE-19 cells (Fig. 1) (Patel et al. 2019; Soe et al. April 2011). The mtDNA haplogroups for each subject and cybrid cell line were identified using polymerase chain reaction (PCR) along with restriction enzyme digestion and mtDNA sequencing as described previously in the study conducted by Patel et al. on $\mathrm{H}$ and $\mathrm{J}$ mtDNA haplogroup cybrid cells (Patel et al. 2019).

\section{Sequencing of mtDNA from $\mathrm{L}, \mathrm{A}, \mathrm{B}$, and D Cybrids}

Peer) reviewing PDF | (2020:02:45720:2:0:NEW 13 Aug 2020) 
161 DNA was extracted from the individual cybrids $(n=7$ for $L$ cybrids, $n=4$ for $[A+B]$ cybrids,

162

163

164

165

166

167

168

169

170

171

172

173

174

175

176

177

178

179

180

181

182

183

184

185

186

187

188

189

190

191

192

193

194

195

196

197

198

199

and $n=3$ for D cybrids) using a kit (DNeasy Blood and Tissue Kit, Qiagen, Germantown, MD).

Sequencing techniques similar to those previously described in the study between $\mathrm{H}$ and $\mathrm{J}$ mtDNA haplogroup cybrids were conducted (Patel et al. 2019). Next Generation Sequencing (NGS) technology was used to sequence both strands of mtDNA independently in both directions. This was done to quantitate the haplogroup-defining single nucleotide polymorphisms (SNPs), private SNPs (not defining haplogroups), and low-frequency heteroplasmy SNPs across the entire mitochondrial genome. NGS technology is capable of deep sequencing (average sequencing depth of 30,000 ; range 1,000 to 100,000 ) and accurately differentiates low-frequency mtDNA heteroplasmy SNPs from DNA modification artifacts. The mtDNA sequences were analyzed using HaploGrep (www.haplogrep.uibk.ac.at) to identify the mtDNA haplogroups (Figs. 2-4, Table 1). Defined SNP changes between the L, [A+B], and D cybrids were obtained using www.Phylotree.org. and Amino acid changes and any associated pathogenesis resulting from differences in SNP variants were verified using www.MitoMap.com and/or www.hmtvar.uniba.it. The rs numbers were identified using www.ncbi.nlm.nih.gov/snp. All of the SNPs identified had a Quality Score of 100 (A Phred-scaled quality score assigned by the variant caller) and Passed all of the Filters (Patel et al. 2019) (Table 2).

\section{Cybrid Cell Lines Culture}

Cybrid cell lines containing mitochondria with either L, $[\mathrm{A}+\mathrm{B}]$, or D haplogroups were cultured in flasks until confluent. They were then plated on a 96-well or 24-well plates depending on the assay. The MTT, JC1 and LDH experiments were performed on 7 different $\mathrm{L}$ cybrids, each with mitochondria from different individuals. The $[\mathrm{A}+\mathrm{B}]$ cybrids represented 4 different individuals. The $\mathrm{D}$ cybrids represented 3 different subjects. Each treatment condition was run in quadruplicate and the experiments repeated twice. The mean values of all cybrids were calculated for both experiments individually. Then these individual means were combined by haplogroup ( $\mathrm{L}$ versus $[\mathrm{A}+\mathrm{B}]$ versus $\mathrm{D}$ ) for the final analyses.

Cells were plated in 96-well plates with each well containing 50,000 cells. After 24 hours, media were removed, and cells were treated with $100 \mu \mathrm{L}$ of $40 \mu \mathrm{M}$ concentration of cisplatin (given as a gift from Professor Bota, UCI Medical Director, Neuro-Oncology Program). Generally, the concentration of cisplatin used to treat cancer cells for 48 hours is $10 \mu \mathrm{M}$. However, a previous study done by Patel et. al on ARPE-19 cybrids containing either H or J mtDNA haplogroups found that the concentration best fit to inhibit these cells was $40 \mu \mathrm{M}$. This was concluded via IC50 analysis which demonstrates the concentration of cisplatin necessary to inhibit cell viability by $50 \%$. As a result, the $40 \mu \mathrm{M}$ concentration was selected for treatment in the current study (Patel et al. 2019). Plates were then incubated at $37^{\circ} \mathrm{C}$ for another 48 hours.

\section{Cellular Metabolic Activity Measured by Tetrazolium Dye (MTT) Assay}


200 The MTT assay was conducted to assess cellular metabolic activity, which was in turn correlated 201 to ATP production and overall cell viability. After the 48-hour incubation period, $10 \mu \mathrm{L}$ of MTT 202 solution (3-(4,5-dimethylthiazol-2-yl)-2,5-diphenyltetrazolium bromide, (Biotium, Hayward, $203 \mathrm{CA}$ ) was added to the $100 \mu \mathrm{L}$ of medium in each well. Plates were then incubated at $37^{\circ} \mathrm{C}$ for 2 204 hours. $100 \mu \mathrm{L}$ of DMSO was directly added into the medium in each well and pipetted up and 205 down until thoroughly mixed. Absorbance was measured on an absorbance reader (BioTek, ELX 206808 , Winooski, VT) at $570 \mathrm{~nm}$ (measured) and $630 \mathrm{~nm}$ (reference). The reference absorbance 207 value was subtracted from the measured value in order to attain true absorbance values. All 208 values were normalized to the average metabolic activity of the untreated-L cybrids. Average 209 values for the cybrids were then compared to the respective untreated cybrids using a two-tailed 210 t-test (GraphPad Prism Software, Inc, San Diego, CA). P $\leq 0.05$ was deemed statistically 211 significant. Each treatment condition was run in quadruplicate, and the entire experiment was 212 repeated twice.

213

214

\section{Mitochondrial Membrane Potential ( $\Delta \Psi \mathrm{m})$ Assay (JC-1 Assay)}

$\mathrm{L},[\mathrm{A}+\mathrm{B}]$, and D cybrids were plated in 24-well plates (100,000 cells/well), incubated 24 hours and, treated with 0 or $40 \mu \mathrm{M}$ of cisplatin for another 48 hours. JC-1 reagent $\left(5,5^{\prime}, 6,6^{\prime}\right.$-tetrachloro$1,1^{\prime}, 3,3^{\prime}$ - tetraethylbenzimidazolylcarbocyanine iodide) (Biotium, Hayward, CA) was added to cultures for 15 minutes. Similar to the study conducted by Patel et. al, a Gemini XPS Microplate Reader (Molecular Devices) was used to measure fluorescence for red (excitation $550 \mathrm{~nm}$ and emission $600 \mathrm{~nm}$ ) and green (excitation $485 \mathrm{~nm}$ and emission $545 \mathrm{~mm}$ ) wavelengths. Intact mitochondria with normal $\Delta \Psi \mathrm{m}$ fluoresced red, while cells with decreased $\Delta \Psi \mathrm{m}$ fluoresced green. Experiments were then analyzed in quadruplicate, and the entire experiment was repeated twice. All values were normalized to the average of the untreated-L cybrids, and cisplatin-treated cybrids were compared to untreated cybrids using a two-tailed t-test to assess for statistical significance (GraphPad Prism Software, Inc.) (Patel et al. 2019).

\section{Mitochondrial Membrane Potential ( $\Delta \Psi \mathrm{m})$ Assay (IncuCyte ${ }^{\circledR}$ Live Cell Analyzer With ARPE-19 Cells)}

After cisplatin treatment, the cybrids showed decreased metabolic activity but the mitochondrial membrane potentials remained unchanged, which was unexpected. Therefore, we conducted additional experiments using the ARPE-19 cell line evaluated with the IncuCyte ${ }^{\circledR}$ Live Cell Analyzer (Sartorius, City, State) and the Nuclight Rapid Red probe (A549 NucLight Red, cat \# 4491) that allowed for comparison of growth/proliferation over 40 hours in cultures treated with $20 \mu \mathrm{M}$ or $40 \mu \mathrm{M}$ cisplatin ( $=7$ per treatment condition). The IncuCyte $\mathbb{B}$ Analyzer captures changes in probes fluorescence and morphologic images in real time. The mitochondrial membrane potential was measured with the JC-1 reagent $\left(5,5^{\prime}, 6,6^{\prime}\right.$-tetrachloro-1, $1^{\prime}, 3,3^{\prime}$ tetraethylbenzimidazolyl-carbocyanine iodide) (Biotium, Hayward, CA) that was added to cultures for 15 minutes. Fluorescence was measured for red (excitation $550 \mathrm{~nm}$ and emission 600 $\mathrm{nm}$ ) and green (excitation $485 \mathrm{~nm}$ and emission $545 \mathrm{~mm}$ ) wavelengths. Intact mitochondria with 
240 241

242

243

244

245

246

247

248

249

250

251

252

253

254

255

256

257

258

259

260

261

262

263

264

265

266

267

268

269

270

271

272

273

274

275

276

277

278

279

normal $\Delta \Psi \mathrm{m}$ appeared red, while cells with decreased $\Delta \Psi \mathrm{m}$ were in a green fluorescent state (n $=7$ wells per treatment condition).

The ARPE-19 cells (ATCC, Manassas, VA); (Invitrogen-Gibco, Carlsbad, CA), which are the wildtype of the Rho 0 receipt cells of the cybrids, were cultured in Dulbecco's modified Eagle's and Ham's nutrient mixture F-12 (1:1 mixture, vol/vol), 0.37\% sodium bicarbonate, $0.058 \% \mathrm{~L}$ glutamine, $10 \%$ fetal bovine serum, antibiotics $(100 \mathrm{U} / \mathrm{ml}$ penicillin $\mathrm{G}, 0.1 \mathrm{mg} / \mathrm{ml}$ streptomycin sulfate, $10 \mu \mathrm{g} / \mathrm{mL}$ gentamicin), $10 \mathrm{mM}$ non-essential amino acids, and an anti-fungal agent (amphotericin-B $2.5 \mu \mathrm{g} / \mathrm{mL}$ ). ARPE-19 cells are a homogeneous, retinal-derived cell line with functional and structural properties similar to human retinal pigment epithelial (RPE) cells (Dunn et al. 1996). All cells within the ARPE-19 culture express RPE-specific markers such as CRALBP, BEST1, and RPE-65 (Moustafa et al. 2017).

\section{Cytotoxicity Assay - Lactate Dehydrogenase Assay (LDH Assay)}

$\mathrm{L},[\mathrm{A}+\mathrm{B}]$, and D cybrids were plated in $96-$ well plates $(10,000$ cells/ well) for 24 hours and treated with 0 or $40 \mu \mathrm{M}$ of cisplatin for another 48 hours. $50 \mu \mathrm{M}$ of supernatant containing the released LDH from each corresponding well was transferred to a new 96-well plate, and $50 \mu \mathrm{M}$ of reaction mixture was subsequently added and gently mixed. The plates were incubated at room temperature for 30 minutes, and the resulting reactions were stopped by adding $50 \mu \mathrm{M}$ of stop solution to each well. Absorbance readings were taken at both $490 \mathrm{~nm}$ and $680 \mathrm{~nm}$ using an absorbance reader (BioTek, ELX 808, Winooski, VT). Percent cytotoxicity levels were calculated using the equation (Treated LDH level - spontaneous LDH level) divided by (Maximum LDH level - spontaneous LDH level) multiplied by one hundred. Average percent cytotoxicity levels were calculated for each ethnic population, normalized to the L haplogroup, and then compared using a two-tailed t-test. $\mathrm{P} \leq 0.05$ was deemed statistically significant. Cytotoxicity levels were analyzed, each treatment condition was run in quadruplicate and the entire experiment was repeated three separate times.

\section{RNA Isolation, Quantitative-Real Time PCR (qRT-PCR)}

$\mathrm{L},[\mathrm{A}+\mathrm{B}]$, and D cybrids were plated in six-well plates $(500,000$ cells/well) and incubated for 24 hours. Cybrid cells were then treated with culture media containing either 0 or $40 \mu \mathrm{M}$ of cisplatin for an additional 48 hours. Trypsinized cells were pelleted, and RNA was isolated according to the manufacturer's protocol (RNeasy Kit, Qiagen, Valencia, CA). Following RNA quantification (Nanodrop 1000, Thermoscientific, Wilmington, DE), the cDNA was synthesized from $2 \mu \mathrm{g}$ of RNA (QuantiTect Reverse Transcription Kit, Qiagen), and used for qRT-PCR (StepOnePlus instrument; Applied Biosystems, Carlsbad, CA). Proprietary, predesigned and validated SYBR Green-based primer assays were used (QuantiTect Primer Assays, Qiagen). Qiagen, the source for the primer assays does not release the sequence of their primers and an internal reference gene number (rs\#) is not provided, however, the identity of each primer assay can be identified via the gene's GenBank accession number (NM) (https://geneglobe.qiagen.com/product- 
280

281

282

283

284

285

286

287

288

289

290

291

292

293

294

295

296

297

298

299

300

301

302

303

304

305

306

307

308

309

310

311

312

313

314

315

316

317

318

319

groups/quantitect-primer-assays). Cancer-related nuclear genes were selected as they are typically the target for many chemotherapeutic treatments and presently have medications that target them. They were examined to understand how variations in mtDNA haplogroups affect retrograde signaling (mitochondria to nucleus) in cells that only vary in their mtDNA. The genes analyzed included ALK (Anaplastic Lymphoma Receptor Tyrosine Kinase, NM_004304), BRCA1 (DNA Repair Associated, NM_007294), EGFR (Epidermal Growth Factor Receptor 1, NM_005228), and ERBB2/HER2 (Erb-b2 Receptor Tyrosine Kinase 2, NM_004448) genes. Similar to the study done by Patel et. al, target cycle thresholds $(\mathrm{Ct})$ values were first compared to the $\mathrm{Ct}$ values of reference genes, and then, comparisons between untreated and cisplatintreated values $(\Delta \Delta \mathrm{Ct})$ were evaluated for statistical significance. Fold differences were quantified using the equation $2^{(\Delta \Delta \mathrm{Ct})}$, and the values for each sample were normalized to that of the untreated. This was done separately for each haplogroup in order to identify a starting base expression level and observe the gene expression fold difference after cisplatin treatment (Tables 3-4) (Patel et al. 2019).

\section{Statistical Analysis}

Statistical analysis of the data were performed by ANOVA (GraphPad Prism, version 5.0). Newman-Keuls multiple-comparison or the two-tailed $t$-tests were used to compare the data within each experiment. Results were normalized to that of the average untreated-L cybrid for each cell study. $\mathrm{P} \leq 0.05$ was considered statistically significant. Error bars representing standard deviation (SD) as well as standard error of the mean (SEM) have been graphed for each assay (Patel et al. 2019).

\section{Results}

\section{Creation of $\mathrm{L}, \mathrm{A}, \mathrm{B}$, and D Cybrids}

Figure 1 represents the cybrid cell creation process resulting in cells with identical nuclei but differing mtDNA haplogroups. The mtDNA haplogroups for each subject and cybrid cell line were verified using polymerase chain reaction (PCR) along with restriction enzyme digestion and mtDNA sequencing as described previously in the study conducted by Patel et al. on $\mathrm{H}$ and $\mathrm{J}$ mtDNA haplogroup cybrid cells ( $L$ cybrids, $n=7$; $[\mathrm{A}+\mathrm{B}]$ cybrids, $\mathrm{n}=4$; and $\mathrm{D}$ cybrids, $\mathrm{n}=3$ ) (Patel et al. 2019).

\section{Sequencing of mtDNA from $L, A, B$, and D Cybrids}

The entire mtDNA from the L, A, B, and D cybrids were sequenced using Next Generation Sequencing (NGS) technology. Table 1 summarizes the mtDNA haplogroup, age and gender for the subjects in this study. Figures 2-4 show individual mtDNA SNPs that define the haplogroup classification of each cybrid. The private SNPs are those that do not define the L, A, B, or D haplogroups (non-haplogroup defining). The unique SNPs are those SNPs not listed in www.mitomap.org or other programs (Figs. 2-4, Table 1) (Patel et al. 2019). Values in the cell and gene expression studies are averages and do not represent any particular SNP variant within 
320

321

322

323

324

325

326

327

328

329

330

331

332

333

334

335

336

337

338

339

340

341

342

343

344

345

346

347

348

349

350

351

352

353

354

355

356

357

358

359

one haplogroup. They are instead representative of the haplogroup-defining SNPs common among all cybrids within a haplogroup. SNP Variants associated with the L, [A+B], and D mtDNA haplogroups as well as the location of the mtDNA nucleotide change, the base pairs changed, their associated rs number, and any associated pathogenesis found in the literature were identified and assessed. Non-synonymous changes present in some but not all haplogroups tested were found at $4824 \mathrm{~A}>\mathrm{G}$, rs ND; $5178 \mathrm{C}>\mathrm{A}$, rs28357984; $5442 \mathrm{~T}>\mathrm{C}$, rs3020601; $7146 \mathrm{G}>\mathrm{A}$, rs372136420; $8701 \mathrm{G}>\mathrm{A}$, rs2000975; $8794 \mathrm{C}>\mathrm{T}$, rs2298007; $10398 \mathrm{G}>\mathrm{A}$, rs2853826; and $13105 \mathrm{G}>\mathrm{A}$, rs2853501 (www.hmtvar.uniba.it and www.phylotree.org) (Table 2).

\section{Relative Cellular Metabolic Activity of Untreated L, A+B, and D Cybrids}

The cellular metabolic activity measured with the MTT assay is representative of the cell viability within the cybrid cultures. The untreated cybrids, representing different maternal ethnic populations (African (L), Hispanic [A+B], or Asian (D) mtDNA haplogroups), had statistically similar relative cellular metabolic activities. All values were normalized to the average of the untreated-L cybrids and displayed as the mean \pm SEM (Fig. 5A). The distribution of each value was also presented in a dot-plot graph representing mean $\pm \mathrm{SD}$ (Fig. 5B). The untreated-L cybrids $(102.4 \% \pm 7.0 \% \mathrm{SEM} ; \mathrm{SD}=21.0 \%, \mathrm{n}=7)$ had similar relative cellular metabolic activity when compared to the untreated-D cybrids $(111.7 \% \pm 4.3 \% \mathrm{SEM} ; \mathrm{SD}=11.3 \%, \mathrm{n}=3, \mathrm{p}$ $=0.311)$ and the untreated-[A+B] cybrids $(95.0 \% \pm 8.5 \% \mathrm{SEM} ; \mathrm{SD}=20.9 \%, \mathrm{n}=4, \mathrm{p}=0.512)$. Untreated-[A+B] cybrids showed similar cellular metabolic activity compared to the untreated-D cybrids $(p=0.0933)$. Experiments were analyzed in quadruplicate, and the entire experiment was repeated twice.

\section{Relative Cellular Metabolic Activity of $\mathrm{L}, \mathrm{A}+\mathrm{B}$, and D Cybrids After Cisplatin Treatment} We found significantly reduced cellular metabolic activity after cisplatin treatment in the $\mathrm{L}$, [A+B], and D cybrids compared to their respective untreated controls (Fig. 6AandB). All values were normalized to the average of the untreated-L cybrids and displayed as the mean $\pm \mathrm{SEM}$ (Fig. 6A). The distribution of each value was also presented in a dot-plot graph representing mean $\pm \mathrm{SD}$ (Fig. 6B). The cisplatin-treated-L cybrids showed the greatest reduction in relative cellular metabolic activity compared to the untreated-L cybrids $(75.0 \% \pm 6.7 \% \mathrm{SEM}$; $\mathrm{SD}=$ $20.0 \%, \mathrm{n}=7 ; 102.4 \% \pm 7.0 \% \mathrm{SEM} ; \mathrm{SD}=21.0 \%, \mathrm{n}=7$, respectively $)(\mathrm{p}=0.0117)$. The cisplatin-treated-D cybrids showed a significant decrease in cell viability compared to the untreated-D cybrids $(86.9 \% \pm 1.6 \% \mathrm{SEM} ; \mathrm{SD}=4.3 \%, \mathrm{n}=3 ; 111.7 \% \pm 4.3 \% \mathrm{SEM} ; \mathrm{SD}=11.3 \%$, $\mathrm{n}=3$, respectively) $(\mathrm{p}=0.0001)$. The cisplatin-treated-[A+B] cybrids also had a statistically significant decrease in cellular metabolic activity compared to their respective untreated-[A+B] cybrids $(70.3 \% \pm 4.5 \% \mathrm{SEM} ; \mathrm{SD}=11.1 \%, \mathrm{n}=4 ; 95.0 \% \pm 8.5 \% \mathrm{SEM} ; \mathrm{SD}=20.9 \%, \mathrm{n}=4$, respectively) $(\mathrm{p}=0.0285)($ Fig. 6AandB). Each treatment was run in quadruplicate and the entire experiment was repeated twice.

\section{Mitochondrial Membrane Potential $(\Delta \Psi \mathrm{m})$ After Cisplatin Treatment}


360

361

362

363

364

365

366

367

368

369

370

371

372

373

374

375

376

377

378

379

380

381

382

383

384

385

386

387

388

389

390

391

392

393

394

395

396

397

398

Mitochondrial membrane potentials for untreated and treated cybrid cells were measured. All values were normalized to the average of the untreated-L cybrids and displayed as the mean \pm SEM (Fig 7A). The distribution of each value was also presented in a dot-plot graph representing mean $\pm \mathrm{SD}$ (Fig. 7B). Results indicated that there was no significant difference in mitochondrial membrane potential in the cisplatin-treated cybrids compared to the untreated cybrids. Cisplatintreated-L cybrids had a relative mitochondrial membrane potential of $108.4 \% \pm 8.2 \% \mathrm{SEM}$; SD $=21.8 \%$ versus untreated-L cybrids $(101.0 \% \pm 11.2 \% \mathrm{SEM} ; \mathrm{SD}=29.5 \%, \mathrm{n}=7, \mathrm{p}=0.602)$. Cisplatin-treated-[A+B] displayed $136.5 \% \pm 33.9 \% \mathrm{SEM}$; $\mathrm{SD}=67.8 \%$ versus untreated-[A+B] cybrids $(147.5 \% \pm 42.0 \% \mathrm{SEM} ; \mathrm{SD}=84.0 \%, \mathrm{n}=4, \mathrm{p}=0.845)$. The cisplatin-treated-D cybrids were observed to have a relative mitochondrial membrane potential of $115.0 \% \pm 3.5 \% \mathrm{SEM}, \mathrm{SD}$ $=7.0 \%$ versus the untreated-D cybrids $(127.3 \% \pm 20.1 \% \mathrm{SEM} ; \mathrm{SD}=40.3 \%, \mathrm{n}=3, \mathrm{p}=0.571)$ (Fig. 7AandB). Each treatment was run in quadruplicate and the entire experiment was repeated twice.

\section{Mitochondrial Membrane Potential $(\Delta \Psi \mathrm{m})$ Assay (IncuCyte ${ }^{\circledR}$ Live Cell Analyzer With ARPE-19 Cells)}

After cisplatin treatment, the cybrids showed decreased metabolic activity but the mitochondrial membrane potentials remained unchanged, which was unexpected. Therefore, we conducted additional experiments using the ARPE-19 cell line that allowed for comparison of growth/proliferation over 40 hours in cultures treated with $20 \mu \mathrm{M}$ or $40 \mu \mathrm{M}$ cisplatin ( $\mathrm{n}=7$ per treatment condition). All values were displayed as the mean \pm SD. Over the first 8 hours of culture, the untreated and cisplatin-treated ARPE-19 cells showed similar rates of growth (Fig. $8 A$ ). By 10 hours the untreated ARPE-19 cells showed an increasing slope of growth compared to the $20 \mu \mathrm{M}$ and $40 \mu \mathrm{M}$ cultures that were stagnant in their growth. By 40 hours, the untreated had a 2-fold higher number of cells than cisplatin-treated cultures. (Untreated $1969 \pm 115$ standard deviation (SD)), versus $20 \mu \mathrm{M}(1023 \pm 81 \mathrm{SD}, \mathrm{p}=0.0006)$ and $40 \mu \mathrm{M}(945 \pm 74 \mathrm{SD}, \mathrm{p}$ $=0.0001)$ (At 40 hours, the $\Delta \Psi \mathrm{m}$ levels were similar between the untreated AREP-19 (1.8993 \pm $0.145 \mathrm{SD})$ versus $20 \mu \mathrm{M}(2.0698 \pm 0.161 \mathrm{SD}, \mathrm{p}=\mathrm{NS})$ and $40 \mu \mathrm{M}(2.0520 \pm 0.162 \mathrm{SD}, \mathrm{p}=\mathrm{NS})$ cisplatin-treated ARPE-19 cultures (Fig. 8B).

\section{Lactate Dehydrogenase Cytotoxicity After Cisplatin Treatment}

The cytotoxicity levels of each of the cybrids were measured with the lactate dehydrogenase (LDH) assay. All values were normalized to the average of the untreated-L cybrids and displayed as the mean $\pm \operatorname{SEM}($ Fig. 9A). The distribution of each value was also presented in a dot-plot graph representing mean $\pm \mathrm{SD}$ (Fig. 9B). When normalized to the L cybrids, there were significantly higher LDH cytotoxicity levels in L cybrids compared to [A+B] cybrids $(111.5 \% \pm$ $16.5 \% \mathrm{SEM} ; \mathrm{SD}=40.5 \%, \mathrm{n}=7$ versus $41.8 \% \pm 9.8 \% \mathrm{SEM} ; \mathrm{SD}=16.9 \%, \mathrm{n}=4$, respectively $)(\mathrm{p}$ $=0.0270)$. The D cybrids trended lower LDH levels but they were not significant $(48.9 \% \pm$ $20.2 \%$ SEM; $\mathrm{SD}=35.0 \%, \mathrm{n}=3, \mathrm{p}=0.0576$ ) compared to the $\mathrm{L}$ cybrids. $\mathrm{LDH}$ cytotoxicity 
399

400

401

402

403

404

405

406

407

408

409

410

411

412

413

414

415

416

417

418

419

420

421

422

423

424

425

426

427

428

429

430

431

432

433

434

435

436

437

levels between the $[\mathrm{A}+\mathrm{B}]$ and $\mathrm{D}$ cybrids were not statistically different $(\mathrm{p}=0.766)($ Fig.

$9 A$ and $B)$. The entire experiment was repeated three separate times.

\section{Gene Expression Levels in L, [A+B], and D Cybrids After Cisplatin Treatment}

ALK (Anaplastic Lymphoma Kinase): Transcription levels for $\mathrm{L}$ cybrids and the combined $[\mathrm{A}+\mathrm{B}]$ cybrids dropped significantly after cisplatin treatment $(0.18$ fold $\pm 0.097, \mathrm{n}=7, \mathrm{p}<$ $0.0001 ; 0.17$ fold $\pm 0.095, \mathrm{n}=4, \mathrm{p}=0.0001$, respectively), while the $\mathrm{D}$ cybrids had no significant change in ALK gene expression $(\mathrm{n}=3, \mathrm{p}=0.290)$ (Tables 3-4).

BRCA1 (Breast Cancer 1): Gene expression levels for all cybrids (L, [A+B], and D) did not significantly change after treatment with cisplatin compared to untreated-control cybrids $(\mathrm{n}=7$, $4,3, \mathrm{p}=0.356,0.294, \mathrm{p}=0.158$, respectively) (Tables 3-4).

EGFR (Epidermal Growth Factor Receptor 1): After cisplatin treatment, cybrids containing L and D mtDNA haplogroups had no significant change in EGFR gene expression compared to their respective untreated-controls $(\mathrm{n}=7, \mathrm{p}=0.301$ and $\mathrm{n}=3, \mathrm{p}=0.218$, respectively).

However, cisplatin-treated cybrids containing $[\mathrm{A}+\mathrm{B}] \mathrm{mtDNA}$ haplogroups significant decreased in EGFR gene expression levels when compared to untreated-[A+B] cybrids $(0.50$ fold $\pm 0.17, \mathrm{n}$ $=4, \mathrm{p}=0.0246)$ (Tables 3-4).

ERBB2/HER2 (Erb-b2 Receptor Tyrosine Kinase 2): Similar to the BRCA1 gene expression levels, ERBB2/HER2 gene expression levels were not significantly different after cisplatin treatment in any of the cybrid cell lines $(\mathrm{L},[\mathrm{A}+\mathrm{B}]$, and $\mathrm{D})$ tested $(\mathrm{n}=7,4,3 ; \mathrm{p}=0.839,0.379$, 0.325, respectively) (Tables 3-4).

\section{Discussion}

\section{Sequencing of the Entire mtDNA}

The NGS technology used to analyze the mtDNA from each of the L, A, B, and D cybrids showed that the majority of SNPs identified were haplogroup defining. The private SNPs (nonhaplogroup defining), unique SNPs (not listed in www.mitomap.org), and heteroplasmy SNPs were found in individual cybrids and not throughout all of the L, A, B, or D cybrids. Similar to the study comparing cybrids with $\mathrm{H}$ and $\mathrm{J}$ mtDNA haplogroups, this suggests that the differential retrograde signaling between the $\mathrm{L}, \mathrm{A}, \mathrm{B}$, and $\mathrm{D}$ mtDNA haplogroups is due to the accumulation of the haplogroup defining SNPs rather than a single mutation or private SNP (Patel et al. 2019). These data are also consistent with another cybrid study which used allelic discrimination and Sanger sequencing to identify the mtDNA haplogroups (Atilano et al. 2015). NGS technology was used for deep sequencing of the mtDNA (ranging from 1,000 to 100,000, with an average depth of 30,000), which allowed for low-level heteroplasmy to be reliably identified (Patel et al. 2019). This method helps distinguish artifact from low-level heteroplasmy because both strands 
438

439 440

441

442

443

444

445

446

447

448

449

450

451

452

453

454

455

456

457

458

459

460

461

462

463

464

465

466

467

468

469

470

471

472

473

474

475

476

477

of mtDNA are independently sequenced in both directions. The role of mtDNA haplogroups in retrograde signaling is still under investigation, and many pathways may still be unidentified.

Haplogroup-defining SNPs were analyzed and the nucleotide changes between the L, [A+B], and D cybrids were identified (Table 2). Non-synonymous changes (causing a change in amino acid) present in some but not all haplogroups tested were found at eight locations. Related pathogenesis to these SNP variants have been associated with diseases such as asthenospermia, atherosclerosis, breast cancer, cardiomyopathy, esophageal cancer, fertilization failure, Fuch's endothelial corneal dystrophy (FECD), glaucoma, diabetes, hypertension, infertility, irritable bowel syndrome, myocardial infarction, neuropathy, osteoarthritis, osteosarcoma, Parkinson's, mobility impairment, neuromuscular disorders, schizophrenia, somatic lung cancer, and thyroid cancer (www.hmtvar.uniba.it and www.phylotree.org) (Table 2). One could speculate that these SNP variants may play a role in the differential susceptibility to cisplatin in $\mathrm{L},[\mathrm{A}+\mathrm{B}]$, and D cybrids because the cybrids have identical nuclei but vary in their mtDNA. Additional studies are needed to better understand the relationship between mtDNA haplogroups and drug susceptibility-related cellular pathways.

\section{Variations within mtDNA in $L, A+B$. and $D$ cybrids are associated with a differential decline in relative cellular metabolic activity after treatment with cisplatin.}

After 48 hours, the untreated L (African maternal descent), [A+B] (Hispanic maternal descent), and D (Asian mitochondrial descent) cybrids had similar levels of cellular metabolic activities.

However, in response to cisplatin treatment, there was a differential decline in relative cellular metabolic activity $(\mathrm{L}>\mathrm{D}>[\mathrm{A}+\mathrm{B}]$ cybrids) compared to their respective untreated cultures with the $[\mathrm{A}+\mathrm{B}]$ cybrids showing the smallest decrease in metabolic activity. One can speculate that if a person with mtDNA containing a more resistant SNP variant, such as haplogroup [A+B], was treated with identical doses of cisplatin compared to an individual with haplogroup $\mathrm{L}$ mitochondria, the first individual might experience signs of resistance to the drug, while the latter would experience a significant drop in cellular metabolic activity in the targeted cells. These data suggest that an individual's mtDNA haplogroup profile may play a role in their response to cisplatin treatment, thereby affecting its efficiency and severity when used in chemotherapy. Understanding how pharmacogenomics play a role in patient treatment, particularly, how the patient's mtDNA SNP profile is associated with variations in drug susceptibility, would allow future treatment programs to focus more on an individual's genetic background in order to achieve more effective results (van Gisbergen et al. 2015). Further studies will be required to better understand the relationship between mtDNA SNP variants and differences in drug susceptibility.

\section{Cisplatin treatment induced apoptosis without significantly disrupting mitochondrial membrane potential.}

Peer] reviewing PDF | (2020:02:45720:2:0:NEW 13 Aug 2020) 
478 Data from the JC-1 assay indicated that when treated with cisplatin, mitochondrial membrane 479 potential in all cybrids was maintained. Surprisingly, L, [A+B], and D cybrids did not show any 480 significant change in mitochondrial membrane potential after cisplatin treatment. OXPHOS 481 related ATP production is dependent on mitochondrial membrane potential, and a drastic 482 decrease or increase in membrane potential in the intermembrane space results in less efficient 483 ATP production via ATP synthase. Cisplatin is known to disrupt mitochondrial membrane

484

485

486

487

488

489

490

491

492

493

494

495

496

497

498

499

500

501

502

503

504

505

506

507

508

509

510

511

512

513

514

515

516

517 potential by inducing the synthesis of pro-apoptotic proteins such as Bcl-2 family proteins, Bax and Bak, which form porous defects within the outer membrane of the mitochondria and result in the release of apoptotic factors such as Cytochrome $c$ into the cytosol, ultimately resulting in cell death (Pabla et al. 2008). However, a failure of the mitochondrial membrane potential to decrease in the case of cybrids containing $\mathrm{L},[\mathrm{A}+\mathrm{B}]$, or D mtDNA haplogroups, suggests that a decrease in cell viability leading to apoptosis was induced by a mechanism that did not disrupt the proton gradient within the intermembrane space of the mitochondria. In a previous study, it was observed that somatic mtDNA mutations affect apoptosis without affecting ROS levels or OXPHOS (Trifunovic et al. 2005). Additionally, a study on renal cells demonstrated that neither mitochondrial membrane potential nor OXPHOS related ATP production significantly changed at any time during cisplatin exposure (Cummings \& Schnellmann 2002).

The ARPE-19 experiments were conducted to verify the cybrid results obtained from the JC-1 mitochondrial membrane potential assays. The ARPE-19 experiments showed the $20 \mu \mathrm{M}$ and 40 $\mu \mathrm{M}$ cisplatin prevented cell proliferation, indicating growth inhibition and decreased cell health but did not cause elimination of the cells. Surprisingly the levels for mitochondrial membrane potential $(\Delta \Psi \mathrm{m})$ were similar in the untreated and cisplatin-treated cultures. This assay relies on the ratio of red (healthy) and green (dead cells) to indicate change in $\Delta \Psi \mathrm{m}$. The red fluorescence is proportional to the potential but diminished in apoptotic or necrotic cells. In ARPE-19 cultures, the cisplatin caused cells to stain more brightly with both red and green intensity, so the final ratio was unchanged (Fig. 8A). This suggests that the cisplatin is not lowering the mitochondrial membrane potential, which agrees with Kleih and colleagues who observed that ovarian cancer cells treated with cisplatin also maintained their mitochondrial membrane potential (Cocetta et al. 2019; Kleih et al. 2019). Similarly, English et. al found that cisplatintreated neuronal cells could maintain and restore their mitochondrial membrane potential through the uptake of cisplatin-resistant mitochondria from astrocytes (English et al. 2020).

An alternative pathway leading to apoptosis as a result of cisplatin treatment may be induced by endoplasmic reticulum (ER) stress. A previous study conducted by Gisbergen et al. demonstrated that ER stress-related apoptosis was induced as a result of cisplatin treatment (van Gisbergen et al. 2015). In that study, cisplatin treatment caused ER stress, which activated Caspase-12 cleavage and consequently resulted in apoptosis. Additionally, in a study conducted by Cumming et al., another ER-associated protein leading to apoptosis was identified. Inhibition of $\mathrm{Ca}^{2+}$ independent phospholipase A2 (ER-iPLA2) resulted in an increase of cisplatin-induced apoptosis 
518 in primary rabbit proximal tubular cultures (Cummings et al. 2004). In a previous study

519 conducted on ARPE cybrid cells containing either H or J mtDNA haplogroups, J cybrids showed

520 a significant decline in mitochondrial membrane potential after cisplatin treatment, while $\mathrm{H}$

521 cybrids did not (Patel et al. 2019). A decrease in mitochondrial membrane potential would

522 suggest a decrease in OXPHOS related ATP production and an increase in glycolytic ATP

523 production. As indicated by Stewart et al., $\rho^{0}$ cells depleted of mitochondria via Ethidium

524 Bromide (EtBr), rely completely on glycolysis for energy production, indicating that OXPHOS

525 inhibition is inversely related to glycolytic ATP production (Stewart et al. 2011). From the study

526 conducted on $\mathrm{H}$ and $\mathrm{J}$ cybrids, along with the current study, one can speculate that the unique

527 composition of an individual's mtDNA plays a role in their susceptibility to cisplatin treatment.

528 Additional studies are needed to better understand the relationship between mtDNA variants and

529 drug susceptibility.

530

531

532

Cybrids with dissimilar mtDNA haplogroups vary in LDH cytotoxicity after cisplatin treatment.

533 Lactate Dehydrogenase cytotoxicity levels measured by the LDH assay illustrated varying results

534 for each of the groups examined. The L cybrids exhibited the highest normalized LDH

535 cytotoxicity levels, which were statistically greater than the $[\mathrm{A}+\mathrm{B}]$ but not the $\mathrm{D}$ cybrids $(\mathrm{p}=$

5360.0270 and $\mathrm{p}=0.0576$, respectively). Additionally, statistical analysis between the $[\mathrm{A}+\mathrm{B}]$

537 cybrids and the $\mathrm{D}$ demonstrated that the two groups did not have statistically different LDH

538 cytotoxicity levels $(\mathrm{p}=0.766)$ (Fig. 9AandB). Cisplatin-induced cytotoxicity is primarily by the

539 mediation of covalent purine adducts within the nuclear (n) DNA that result in disruption of

540 transcription and replication, consequently leading to cell death (Dasari \& Tchounwou 2014).

541 One can speculate that nDNA adduct formation leading to extracellular cytotoxicity is less

542 prevalent in cybrids containing $[\mathrm{A}+\mathrm{B}] \mathrm{mtDNA}$ haplogroups compared to cybrids containing $\mathrm{L}$

543 mtDNA haplogroups. In a previous study conducted by Kohno et al. on cancer cells, it was

544 determined that the prevalence of guanine base sequences within the mtDNA was a determining

545 factor for the ability of cisplatin to bind effectively and form adducts within the DNA, therefore

546 supporting the idea that cisplatin-induced cytotoxicity depended on the unique profile of the

547 individual's mtDNA (Kohno et al. 2015). Variations in cisplatin-induced cytotoxicity between

548 cybrids with different mtDNA may suggest that mtDNA SNP variants play a key role in the

549 extent to which adducts form. Additional studies are needed to better understand the relationship

550

551

552

553 between mtDNA haplogroups and DNA adduct formation.

554 Varied Gene Expression Levels Among Experimented mtDNA Haplogroups:

$555 A L K$ : We examined the $A L K$ gene as it is a common biomarker in patients with non-small-cell

556 lung cancer (NSCLC) and is the primary target of many chemotherapeutic treatments used to

557 treat NSCLC and anaplastic large cell lymphomas (ALCL). (Holla et al. 2017). Cybrids 
558

559

560

561

562

563

564

565

566

567

568

569

570

571

572

573

574

575

576

577

578

579

580

581

582

583

584

585

586

587

588

589

590

591

592

593

594

595

596

597

containing $\mathrm{L}$ or $[\mathrm{A}+\mathrm{B}]$ mtDNA haplogroups had significantly decreased ALK gene expression levels compared to their respective untreated controls, while the cybrids containing D mtDNA haplogroups did not have a significant change compared to their respective controls (Tables 3-4). The $A L K$ gene codes for a receptor tyrosine kinase in the transmembrane region, and plays an important role in early brain and nervous system development (Hallberg \& Palmer 2016; Webb et al. 2009). High ALK gene expression values have been associated with neuroblastoma formation, and the presence of non-small cell lung cancers (NSCLC) (Holla et al. 2017). ALK inhibition has also been a chemotherapeutic target in treatments of these cancers. In the cell culture studies, the D cybrids had higher trending relative cellular metabolic activity than that of cybrids containing $\mathrm{L}$ or $[\mathrm{A}+\mathrm{B}] \mathrm{mtDNA}$ haplogroups. Accelerated cellular metabolic activity is a fundamental characteristic of cancer cells, and such behavior exhibited by cybrids containing D mtDNA haplogroups may represent cancer cell-like traits (Mizutani et al. 2009). These data are significant as it suggests that gene expression values in nuclear genes can be altered depending on the particular mtDNA haplogroup present (Cocetta et al. 2019; da Cunha et al. 2015; Patel et al. 2019). Our findings support this because all cybrids contained identical nDNA and media culture conditions but differed in their specific mtDNA haplogroups, therefore, it is unlikely that nDNA contributed to the differences in cisplatin susceptibility. This suggests that the variation in mtDNA can modulate retrograde signaling (mitochondria to nucleus) that results in varied gene expression for the $A L K$ gene. The mechanism for this occurrence is not fully understood.

EGFR: The EGFR gene as it is a biomarker used to evaluate the efficacy of chemotherapeutic treatments for patients with NSCLC (Wang et al. 2018). After cisplatin treatment, cybrid cells containing L and D mtDNA haplogroups had no significant change in EGFR gene expression compared to untreated cybrids. However, cybrids containing the $[\mathrm{A}+\mathrm{B}] \mathrm{mtDNA}$ haplogroups had a significant change in EGFR gene expression levels and dropped 50.8\% $\pm 17.1 \%$ when compared to their respective untreated cybrids $(\mathrm{p}=0.0246)($ Tables $3-4)$. The EGFR gene codes for a transmembrane glycoprotein that binds to epidermal growth factors, and expression of this gene is associated with cell proliferation. In an in vivo study on patients with NSCLC, degradation of the EGFR gene occurred as a result of platinum-based chemotherapy treatment (Wang et al. 2018). Additionally, Wang et al. concluded that the EGFR gene became highly unstable as a result of the chemotherapy treatment, and that $E G F R$ expression levels dropped significantly in some patients while remaining similar in others (Wang et al. 2018). In a different study conducted in vivo, cisplatin treatment resulted in EGFR phosphorylation and subsequent ubiquitination and degradation (Ahsan et al. 2010). This indicated that those individuals with decreased $E G F R$ levels were more susceptible to negative mutations and, as a result, more susceptible to the treatment than those with no significant decrease in $E G F R$ levels. Results from the current study suggest that patients with $[A+B]$ mtDNA haplogroups may express certain factors that result in their EGFR gene to become significantly more unstable than patients with $\mathrm{L}$ or D mtDNA haplogroups after treatment with cisplatin. These data suggest that expression levels of nuclear genes can be altered depending on the particular mtDNA haplogroup present 
598 (Cocetta et al. 2019; da Cunha et al. 2015; Patel et al. 2019). Our findings show that different

599

600

601

602

603

604

605

606

607

608

609

610

611

612

613

614

615

616

617

618

619

620

621

622

623

624

625

626

627

628

629

630

631

632

633

634

635

636

637

mtDNA variants can alter the expression levels the EGFR gene.

\section{Similar Gene Expression Levels Among Experimented mtDNA Haplogroups:}

BRCA1: The BRCA1 gene was analyzed because it is a common biomarker used to understand the efficacy of chemotherapeutic treatments in patients with breast and ovarian cancers (Quinn et al. 2007; Welcsh \& King 2001). Gene expression levels for all cybrids (L, [A+B], and D) tested did not significantly change, relative to their respective untreated group, after treatment with cisplatin ( $\mathrm{p}=0.356,0.294$, and 0.158 respectively) (Tables $3-4)$. The BRCA1 gene encodes a nuclear phosphoprotein that plays a role in maintaining genomic stability, and germline mutations within this gene have been highly associated with breast and ovarian cancers (Welcsh \& King 2001). In an in vivo study conducted by Quinn et al., BRCA1 gene expression levels were found to be directly correlated with overall survival in patients with ovarian cancer (Quinn et al. 2007). Results from the current study indicate that the variation in mtDNA within the varying cybrids did not significantly change the $B R C A l$ levels of the cybrids. This suggests that the $\mathrm{L},[\mathrm{A}+\mathrm{B}]$, and D mtDNA haplogroups in ARPE cybrids may not have a significant effect on the gene expression pathways associated with the BRCAl gene.

ERBB2/HER2: We examined the ERRB2/HER2 gene as it is a common biomarker used to assess patients with breast cancer (Birnbaum et al. 2009). Similar to the $B R C A 1$ gene expression levels, $E R B B 2 / H E R 2$ gene expression levels were not significantly different after cisplatin treatment in all of the cybrid cells (L, $[\mathrm{A}+\mathrm{B}]$, and $\mathrm{D})(\mathrm{p}=0.839,0.379,0.325$ respectively) (Tables 3-4). Unlike the $B R C A 1$ gene, activation and overexpression rather than mutations of this gene have been shown in numerous cancers (breast cancer and ovarian cancer) (Birnbaum et al. 2009). Stable gene expression levels of the ERBB2/HER2 gene in the L, [A+B], and D cybrids after treatment suggest that the mtDNA SNP variants do not significantly alter pathways associated with $E R B B 2 / H E R 2$ gene expression.

\section{Conclusions}

The efficacy of drug use to treat cancer pathology is determined by the drug's ability to efficiently reduce the effect of or inhibit the disease; however, drug susceptibility has been observed to vary between patients. This variation has been assumed to be a consequence of differences in nDNA, epigenetics, or some other external factors. This study was conducted to assess the consequences of variations within the mtDNA in patients of African, Hispanic, and Asian maternal descent after treatment with the platinum drug cisplatin. The goal of this study was to obtain greater insight into the role of mitochondria, along with its unique genomic information, in drug susceptibility, specifically pathways that promote cisplatin resistance. We used the cybrid model, which are cell lines that contain identical nDNA and media culture conditions but vary only in the specific mtDNA haplogroup profile of each individual. Although nDNA and epigenetic factors may play a role in a patient's response to cisplatin, they would not

Peer) reviewing PDF | (2020:02:45720:2:0:NEW 13 Aug 2020) 
638 account for variations in response to cisplatin in the cybrid model as the only variable is the

639

640

641

642

643

644

645

646

647

648

649

650

651

652

653

654

655

656

657

658

659

660

661

662

663

664

665

666

667

668

669

670

671

672

673

674

675

676

677

mitochondrial genome. In summary, cybrid cells with mtDNA haplogroups representing different racial/ethnic populations, displayed unique overall results in the various cell assays and gene expression studies (Table 3). If mtDNA played no role in drug susceptibility, the effects of cisplatin would be expected to be similar throughout the study. However, L, [A+B], and D cybrids displayed dissimilar results, indicating that the variations in mtDNA are associated with variations in drug responses. The mechanism for this variation is not yet fully understood, and further studies are needed to understand this process completely.

Future studies will focus on examining similar biological pathways in cybrid cells lines with other mtDNA haplogroups to obtain a greater understanding of drug susceptibility in relation to maternal ethnic descent. Understanding the role of mtDNA haplogroups in drug resistance could potentially improve drug treatment efficiency in vivo, and lead to a greater knowledge of pharmacogenomics as well as lead to a more individualized approach to treatment methods.

\section{Acknowledgements}

We wish to thank the subjects who participated in this study. This work was supported by the Discovery Eye Foundation, Polly and Michael Smith, Edith and Roy Carver, and NEI R01 EY0127363 (MCK). Supported by an Unrestricted Departmental Grant from Research to Prevent Blindness. We acknowledge the support of the Institute for Clinical and Translational Science (ICTS) at University of California Irvine. There was no additional external funding received for this study.

\section{References}

Ahsan A, Hiniker SM, Ramanand SG, Nyati S, Hegde A, Helman A, Menawat R, Bhojani MS, Lawrence TS, and Nyati MK. 2010. Role of epidermal growth factor receptor degradation in cisplatin-induced cytotoxicity in head and neck cancer. Cancer research 70:2862-2869. 10.1158/0008-5472.CAN-09-4294

Amable L. 2016. Cisplatin resistance and opportunities for precision medicine. Pharmacol Res 106:27-36. 10.1016/j.phrs.2016.01.001

Atilano SR, Malik D, Chwa M, Cáceres-Del-Carpio J, Nesburn AB, Boyer DS, Kuppermann BD, Jazwinski SM, Miceli MV, Wallace DC, Udar N, and Kenney MC. 2015. Mitochondrial DNA variants can mediate methylation status of inflammation, angiogenesis and signaling genes. Hum Mol Genet 24:4491-4503. 10.1093/hmg/ddv173

Birnbaum D, Sircoulomb F, and Imbert J. 2009. A reason why the ERBB2 gene is amplified and not mutated in breast cancer. Cancer cell international 9:5-5. 10.1186/1475-2867-9-5

Boulikas T, and Vougiouka M. 2004. Recent clinical trials using cisplatin, carboplatin and their combination chemotherapy drugs (review). Oncology reports 11:559-595.

Cocetta V, Ragazzi E, and Montopoli M. 2019. Mitochondrial Involvement in Cisplatin Resistance. Int J Mol Sci 20. 10.3390/ijms20143384

Peer) reviewing PDF | (2020:02:45720:2:0:NEW 13 Aug 2020) 
678 Cummings BS, McHowat J, and Schnellmann RG. 2004. Role of an endoplasmic reticulum Ca2+-

679

680

681

682

683

684

685

686

687

688

689

690

691

692

693

694

695

696

697

698

699

700

701

702

703

704

705

706

707

708

709

710

711

712

713

714

715

716

717

718

719

720 independent phospholipase $\mathrm{A} 2$ in cisplatin-induced renal cell apoptosis. The Journal of pharmacology and experimental therapeutics 308:921-928. 10.1124/jpet.103.060541

Cummings BS, and Schnellmann RG. 2002. Cisplatin-induced renal cell apoptosis: caspase 3dependent and -independent pathways. J Pharmacol Exp Ther 302:8-17. 10.1124/jpet.302.1.8

Czarnecka AM, and Bartnik E. 2011. The Role of the Mitochondrial Genome in Ageing and Carcinogenesis. Journal of Aging Research 2011:1-10. 10.4061/2011/136435

da Cunha FM, Torelli NQ, and Kowaltowski AJ. 2015. Mitochondrial Retrograde Signaling: Triggers, Pathways, and Outcomes. Oxid Med Cell Longev 2015:482582. $10.1155 / 2015 / 482582$

Damia G, and Broggini M. 2019. Platinum Resistance in Ovarian Cancer: Role of DNA Repair. Cancers (Basel) 11. 10.3390/cancers11010119

Dasari S, and Tchounwou PB. 2014. Cisplatin in cancer therapy: molecular mechanisms of action. European journal of pharmacology 740:364-378. 10.1016/j.ejphar.2014.07.025

Devarajan P, Savoca M, Castaneda MP, Park MS, Esteban-Cruciani N, Kalinec G, and Kalinec F. 2002. Cisplatin-induced apoptosis in auditory cells: role of death receptor and mitochondrial pathways. Hear Res 174:45-54. 10.1016/s0378-5955(02)00634-2

Dunn KC, Aotaki-Keen AE, Putkey FR, and Hjelmeland LM. 1996. ARPE-19, a human retinal pigment epithelial cell line with differentiated properties. Exp Eye Res 62:155-169. 10.1006/exer.1996.0020

English K, Shepherd A, Uzor NE, Trinh R, Kavelaars A, and Heijnen CJ. 2020. Astrocytes rescue neuronal health after cisplatin treatment through mitochondrial transfer. Acta Neuropathol Commun 8:36. 10.1186/s40478-020-00897-7

Florea A-M, and Büsselberg D. 2011. Cisplatin as an Anti-Tumor Drug: Cellular Mechanisms of Activity, Drug Resistance and Induced Side Effects. Cancers 3:1351-1371. 10.3390/cancers3011351

Gottesman MM, Lavi O, Hall MD, and Gillet JP. 2016. Toward a Better Understanding of the Complexity of Cancer Drug Resistance. Annu Rev Pharmacol Toxicol 56:85-102. 10.1146/annurev-pharmtox-010715-103111

Ha Y-N, Sung HY, Yang S-D, Chae YJ, Ju W, and Ahn J-H. 2018. Epigenetic modification of $\alpha-\mathrm{N}-$ acetylgalactosaminidase enhances cisplatin resistance in ovarian cancer. The Korean journal of physiology \& pharmacology : official journal of the Korean Physiological Society and the Korean Society of Pharmacology 22:43-51. 10.4196/kjpp.2018.22.1.43

Hallberg B, and Palmer RH. 2016. The role of the ALK receptor in cancer biology. Annals of Oncology 27:iii4-iii15. 10.1093/annonc/mdw301

Han XJ, Shi SL, Wei YF, Jiang LP, Guo MY, Wu HL, and Wan YY. 2017. Involvement of mitochondrial dynamics in the antineoplastic activity of cisplatin in murine leukemia L1210 cells. Oncol Rep 38:985-992. 10.3892/or.2017.5765

Holla VR, Elamin YY, Bailey AM, Johnson AM, Litzenburger BC, Khotskaya YB, Sanchez NS, Zeng J, Shufean MA, Shaw KR, Mendelsohn J, Mills GB, Meric-Bernstam F, and Simon GR. 2017. ALK: a tyrosine kinase target for cancer therapy. Cold Spring Harbor molecular case studies 3:a001115-a001115. 10.1101/mcs.a001115 
721

722

723

724

725

726

727

728

729

730

731

732

733

734

735

736

737

738

739

740

741

742

743

744

745

746

747

748

749

750

751

752

753

754

755

756

757

758

759

760

761

762

763

764
Housman G, Byler S, Heerboth S, Lapinska K, Longacre M, Snyder N, and Sarkar S. 2014. Drug Resistance in Cancer: An Overview. Cancers 6:1769-1792. 10.3390/cancers6031769

Jarrett S, Lin H, Godley B, and Boulton M. 2008. Mitochondrial DNA damage and its potential role in retinal degeneration. Progress in Retinal and Eye Research 27:596-607. 10.1016/j.preteyeres.2008.09.001

Jing L, Su L, and Ring BZ. 2014. Ethnic background and genetic variation in the evaluation of cancer risk: a systematic review. PLoS ONE 9:e97522. 10.1371/journal.pone.0097522

Kenney MC, Chwa M, Atilano SR, Falatoonzadeh P, Ramirez C, Malik D, Tarek M, Cáceres-delCarpio J, Nesburn AB, Boyer DS, Kuppermann BD, Vawter M, Jazwinski SM, Miceli M, Wallace DC, and Udar N. 2014a. Inherited mitochondrial DNA variants can affect complement, inflammation and apoptosis pathways: insights into mitochondrial-nuclear interactions. Hum Mol Genet 23:3537-3551. 10.1093/hmg/ddu065

Kenney MC, Chwa M, Atilano SR, Falatoonzadeh P, Ramirez C, Malik D, Tarek M, del Carpio JC, Nesburn AB, Boyer DS, Kuppermann BD, Vawter MP, Jazwinski SM, Miceli MV, Wallace DC, and Udar N. 2014b. Molecular and bioenergetic differences between cells with African versus European inherited mitochondrial DNA haplogroups: Implications for population susceptibility to diseases. Biochimica et Biophysica Acta (BBA) - Molecular Basis of Disease 1842:208-219. 10.1016/j.bbadis.2013.10.016

Kenney MC, Chwa M, Atilano SR, Pavlis JM, Falatoonzadeh P, Ramirez C, Malik D, Hsu T, Woo G, Soe K, Nesburn AB, Boyer DS, Kuppermann BD, Jazwinski SM, Miceli MV, Wallace DC, and Udar N. 2013. Mitochondrial DNA Variants Mediate Energy Production and Expression Levels for CFH, C3 and EFEMP1 Genes: Implications for Age-Related Macular Degeneration. PLOS ONE 8:e54339-e54339. 10.1371/journal.pone.0054339

Kleih M, Böpple K, Dong M, Gaißler A, Heine S, Olayioye MA, Aulitzky WE, and Essmann F. 2019. Direct impact of cisplatin on mitochondria induces ROS production that dictates cell fate of ovarian cancer cells. Cell Death Dis 10:851. 10.1038/s41419-019-2081-4

Kohno K, Wang K-Y, Takahashi M, Kurita T, Yoshida Y, Hirakawa M, Harada Y, Kuma A, Izumi H, and Matsumoto S. 2015. Mitochondrial Transcription Factor A and Mitochondrial Genome as Molecular Targets for Cisplatin-Based Cancer Chemotherapy. International journal of molecular sciences 16:19836-19850. 10.3390/ijms160819836

Marrache S, Pathak RK, and Dhar S. 2014. Detouring of cisplatin to access mitochondrial genome for overcoming resistance. Proc Natl Acad Sci U S A 111:10444-10449. 10.1073/pnas.1405244111

Marullo R, Werner E, Degtyareva N, Moore B, Altavilla G, Ramalingam SS, and Doetsch PW. 2013. Cisplatin induces a mitochondrial-ROS response that contributes to cytotoxicity depending on mitochondrial redox status and bioenergetic functions. PLOS ONE 8:e81162. 10.1371/journal.pone.0081162

Meijera C, van Luyn MJ, Nienhuis EF, Blom N, Mulder NH, and de Vries EG. 2001. Ultrastructural morphology and localisation of cisplatin-induced platinum-DNA adducts in a cisplatinsensitive and -resistant human small cell lung cancer cell line using electron microscopy. Biochemical pharmacology 61:573-578.

Mizutani S, Miyato Y, Shidara Y, Asoh S, Tokunaga A, Tajiri T, and Ohta S. 2009. Mutations in the mitochondrial genome confer resistance of cancer cells to anticancer drugs. Cancer Science 100:1680-1687. 10.1111/j.1349-7006.2009.01238.x 
765

766

767

768

769

770

771

772

773

774

775

776

777

778

779

780

781

782

783

784

785

786

787

788

789

790

791

792

793

794

795

796

797

798

799

800

801

802

803

804

805

806

807

Moustafa MT, Ramirez C, Schneider K, Atilano SR, Limb GA, Kuppermann BD, and Kenney MC. 2017. Protective Effects of Memantine on Hydroquinone-Treated Human Retinal Pigment Epithelium Cells and Human Retinal Müller Cells. J Ocul Pharmacol Ther 33:610619. 10.1089/jop.2016.0129

O'Byrne KJ, Barr MP, and Gray SG. 2011. The role of epigenetics in resistance to Cisplatin chemotherapy in lung cancer. Cancers 3:1426-1453. 10.3390/cancers3011426

O'Donnell PH, and Dolan ME. 2009. Cancer Pharmacoethnicity: Ethnic Differences in Susceptibility to the Effects of Chemotherapy. Clinical Cancer Research 15:4806-4814. 10.1158/1078-0432.CCR-09-0344

Pabla N, Huang S, Mi QS, Daniel R, and Dong Z. 2008. ATR-Chk2 signaling in p53 activation and DNA damage response during cisplatin-induced apoptosis. J Biol Chem 283:6572-6583. 10.1074/jbc.M707568200

Park MS, De Leon M, and Devarajan P. 2002. Cisplatin induces apoptosis in LLC-PK1 cells via activation of mitochondrial pathways. J Am Soc Nephrol 13:858-865.

Patel TH, Norman L, Chang S, Abedi S, Liu C, Chwa M, Atilano SR, Thaker K, Lu S, Jazwinski SM, Miceli MV, Udar N, Bota D, and Kenney MC. 2019. European mtDNA Variants Are Associated With Differential Responses to Cisplatin, an Anticancer Drug: Implications for Drug Resistance and Side Effects. Frontiers in Oncology 9:640-640. 10.3389/fonc. 2019.00640

Penta JS, Johnson FM, Wachsman JT, and Copeland WC. 2001. Mitochondrial DNA in human malignancy. Mutat Res 488:119-133. 10.1016/s1383-5742(01)00053-9

Quinn JE, James CR, Stewart GE, Mulligan JM, White P, Chang GKF, Mullan PB, Johnston PG, Wilson RH, and Harkin DP. 2007. BRCA1 mRNA Expression Levels Predict for Overall Survival in Ovarian Cancer after Chemotherapy. Clinical Cancer Research 13:7413-7420. 10.1158/1078-0432.CCR-07-1083

Rose MC, Kostyanovskaya E, and Huang RS. 2014. Pharmacogenomics of cisplatin sensitivity in non-small cell lung cancer. Genomics, proteomics \& bioinformatics 12:198-209. 10.1016/j.gpb.2014.10.003

Siddik ZH. 2003. Cisplatin: mode of cytotoxic action and molecular basis of resistance. Oncogene 22:7265-7279. 10.1038/sj.onc.1206933

Singh KK, Russell J, Sigala B, Zhang Y, Williams J, and Keshav KF. 1999. Mitochondrial DNA determines the cellular response to cancer therapeutic agents. Oncogene 18:6641-6646. 10.1038/sj.onc.1203056

Soe K, Chwa M, Pham K, Udar N, Jazwinski SM, Miceli M, and Kenney MC. April 2011. Developing Human ARPE-19 Cybrid Cell Lines from Different Haplogroups Related to Age-related Macular Degeneration (AMD). Investigate Ophthalmology \& Visual Science.

Stewart DJ. 2007. Mechanisms of resistance to cisplatin and carboplatin. Critical Reviews in Oncology/Hematology 63:12-31. 10.1016/J.CRITREVONC.2007.02.001

Stewart JD, Schoeler S, Sitarz KS, Horvath R, Hallmann K, Pyle A, Yu-Wai-Man P, Taylor RW, Samuels DC, Kunz WS, and Chinnery PF. 2011. POLG mutations cause decreased mitochondrial DNA repopulation rates following induced depletion in human fibroblasts. Biochimica et Biophysica Acta (BBA) - Molecular Basis of Disease 1812:321-325. 10.1016/J.BBADIS.2010.11.012

PeerJ reviewing PDF | (2020:02:45720:2:0:NEW 13 Aug 2020) 
808 Tan DS, Mok TS, and Rebbeck TR. 2016. Cancer Genomics: Diversity and Disparity Across

809

810

811

812

813

814

815

816

817

818

819

820

821

822

823

824

825

826

827

828

829

830

831

832

833

834

835

836

837

838

839

840

841

842 Ethnicity and Geography. J Clin Oncol 34:91-101. 10.1200/JCO.2015.62.0096

Trifunovic A, Hansson A, Wredenberg A, Rovio AT, Dufour E, Khvorostov I, Spelbrink JN, Wibom $R$, Jacobs $H T$, and Larsson NG. 2005. Somatic mtDNA mutations cause aging phenotypes without affecting reactive oxygen species production. Proc Natl Acad Sci U S A 102:17993-17998. 10.1073/pnas.0508886102

Tsuyoshi H, Wong VKW, Han Y, Orisaka M, Yoshida Y, and Tsang BK. 2017. Saikosaponin-d, a calcium mobilizing agent, sensitizes chemoresistant ovarian cancer cells to cisplatininduced apoptosis by facilitating mitochondrial fission and G2/M arrest. Oncotarget 8:99825-99840. 10.18632/oncotarget.21076

van Gisbergen MW, Voets AM, Starmans MHW, de Coo IFM, Yadak R, Hoffmann RF, Boutros PC, Smeets HJM, Dubois L, and Lambin P. 2015. How do changes in the mtDNA and mitochondrial dysfunction influence cancer and cancer therapy? Challenges, opportunities and models. Mutation Research/Reviews in Mutation Research 764:16-30. 10.1016/j.mrrev.2015.01.001

Wang Y, Ma X, Wei Y, Ma D, and Gong P. 2018. Effect of platinum-based chemotherapy on EGFR gene mutation status in lung adenocarcinoma. Medicine 97:e9602-e9602. 10.1097/MD.0000000000009602

Webb TR, Slavish J, George RE, Look AT, Xue L, Jiang Q, Cui X, Rentrop WB, and Morris SW. 2009. Anaplastic lymphoma kinase: role in cancer pathogenesis and small-molecule inhibitor development for therapy. Expert review of anticancer therapy 9:331-356. 10.1586/14737140.9.3.331

Welcsh PL, and King M-C. 2001. BRCA1 and BRCA2 and the genetics of breast and ovarian cancer. Human Molecular Genetics 10:705-713. 10.1093/hmg/10.7.705

Yáñez JA, Teng XW, Roupe KA, Fariss MW, and Davies NM. 2003. Chemotherapy induced gastrointestinal toxicity in rats: involvement of mitochondrial DNA, gastrointestinal permeability and cyclooxygenase -2. J Pharm Pharm Sci 6:308-314.

Yasuda SU, Zhang L, and Huang SM. 2008. The Role of Ethnicity in Variability in Response to Drugs: Focus on Clinical Pharmacology Studies. Clinical Pharmacology \& Therapeutics 84:417-423. 10.1038/clpt.2008.141

Ziliak D, Gamazon ER, LaCroix B, Kyung Im H, Wen Y, and Huang RS. 2012. Genetic Variation That Predicts Platinum Sensitivity Reveals the Role of miR-193b* in Chemotherapeutic Susceptibility. Molecular Cancer Therapeutics 11:2054-2061. 10.1158/1535-7163.MCT$12-0221$ 


\section{Figure 1}

Creation of cybrid cells with identical nuclei but varying mtDNA.

Cytoplasmic hybrids (cybrids) were created by fusing ARPE-19 Rho0 (mtDNA free)cells with platelets isolated from peripheral blood from individuals of either $L$ (African), $[A+B]$ (Hispanic), or D (Asian) maternal descent. Rho0cells were initially obtained by treating ARPE-19 cells with small doses of Ethidium Bromide (EtBr) over many passages until they lacked mitochondria. Once the cells were depleted of their mitochondria, they were fused with the obtained platelets using polyethylene glycol fusion. These platelets lacked nuclear (n) DNA, and only contained mitochondrial (mt) DNA. Once fused, the created cybrids contained identical nDNA and the particular mtDNA obtained from the specified patient's platelets. The mtDNA haplogroups for each subject and cybrid cell line were identified using polymerase chain reaction (PCR) along with restriction enzyme digestion and mtDNA sequencing. 


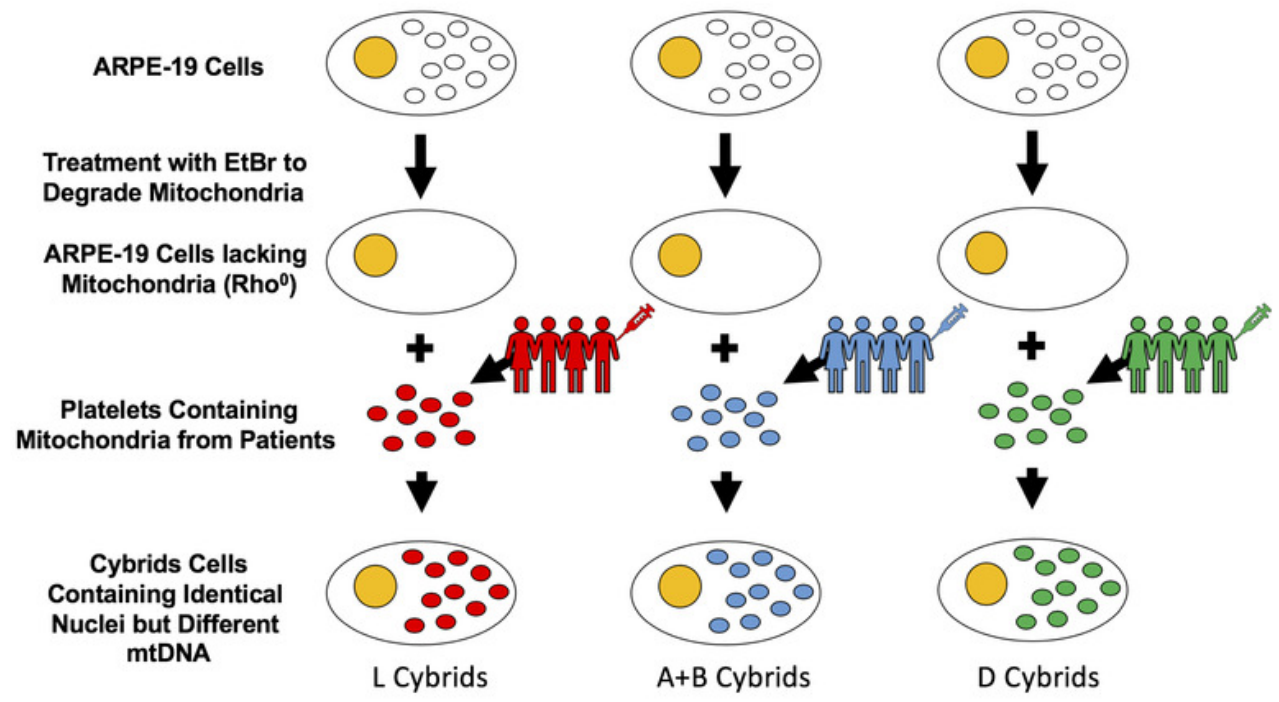

African Maternal Decent




\section{Figure 2}

Mitochondrial SNP variants associated with the various L mtDNA haplogroup subtypes used in this study.

Platelets obtained from patients were sequenced using a kit (DNeasy Blood and Tissue Kit, Qiagen, Germantown, MD), and found to be in the $L$ mtDNA haplogroup ( $n=7)$. The $L m t D N A$ haplogroup is associated with individuals from African maternal descent. The specific variants of those in the L mtDNA haplogroup were identified and their phylogenic tree is displayed. These variants include L0a1a1, L1b1a, L1b1a7, L1b2a, L1c2a1, L2b2, and L3elala. Next Generation Sequencing (NGS) technology was used to sequence both strands of mtDNA independently in both directions. This was done to quantitate the haplogroupdefining single nucleotide polymorphisms (SNPs), private SNPs (not defining haplogroups), and low-frequency heteroplasmy SNPs across the entire mitochondrial genome. The mtDNA sequences were analyzed using HaploGrep (www.haplogrep.uibk.ac.at) to identify the mtDNA haplogroups. SNP variants were verified using www.MitoMap.com, www.Phylotree.org, and/or www.hmtvar.uniba.it. 


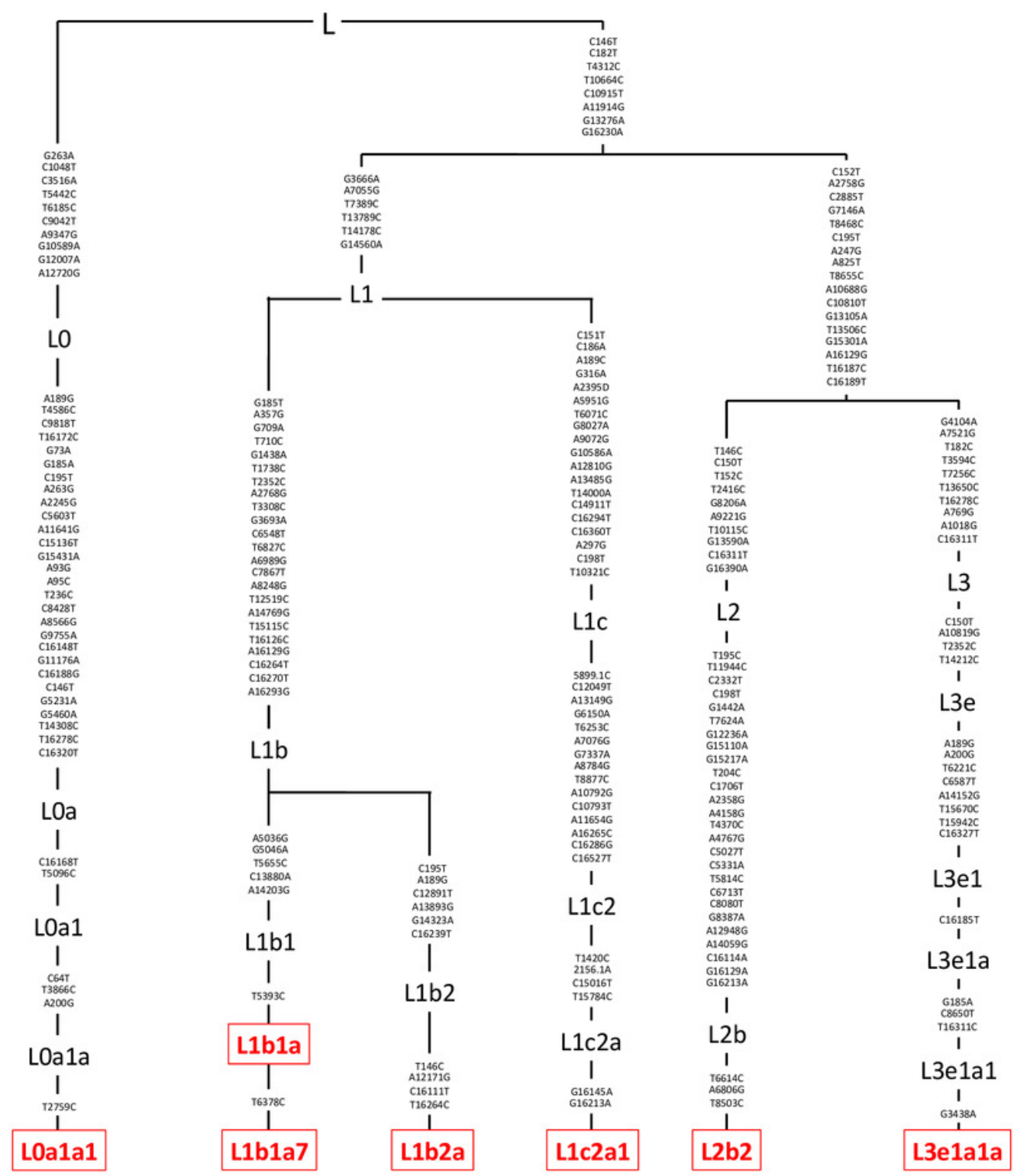




\section{Figure 3}

Mitochondrial SNP variants associated with the A and B mtDNA haplogroups used in this study.

Platelets obtained from patients were sequenced using a kit (DNeasy Blood and Tissue Kit, Qiagen, Germantown, MD), and found to be in the A or B mtDNA haplogroups ( $n=4)$. (A) The A mtDNA haplogroup is associated with individuals from Hispanic maternal descent. The specific variants of those in the A mtDNA haplogroup were identified and their phylogenic tree is displayed. These variants include $A 2$ and $A 2 w$. (B) The B mtDNA haplogroup is also associated with individuals from Hispanic maternal descent. The specific variants of those in the $B$ mtDNA haplogroup were identified and their phylogenic tree is displayed. These variants include B and B2a. Next Generation Sequencing (NGS) technology was used to sequence both strands of mtDNA independently in both directions. This was done to quantitate the haplogroup-defining single nucleotide polymorphisms (SNPs), private SNPS (not defining haplogroups), and low-frequency heteroplasmy SNPs across the entire mitochondrial genome. The mtDNA sequences were analyzed using HaploGrep (www.haplogrep.uibk.ac.at) to identify the mtDNA haplogroups. SNP variants were verified using www.MitoMap.com, www.Phylotree.org, and/or www.hmtvar.uniba.it. 
A

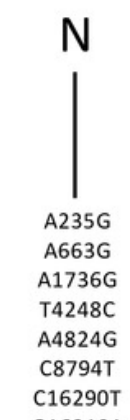

G16319A

A
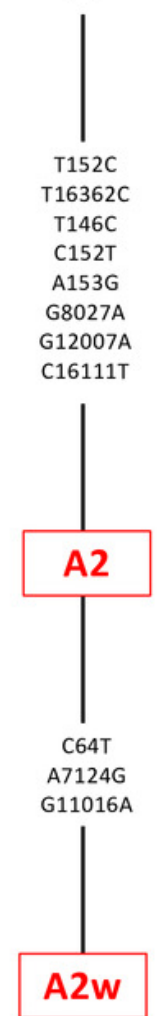

B

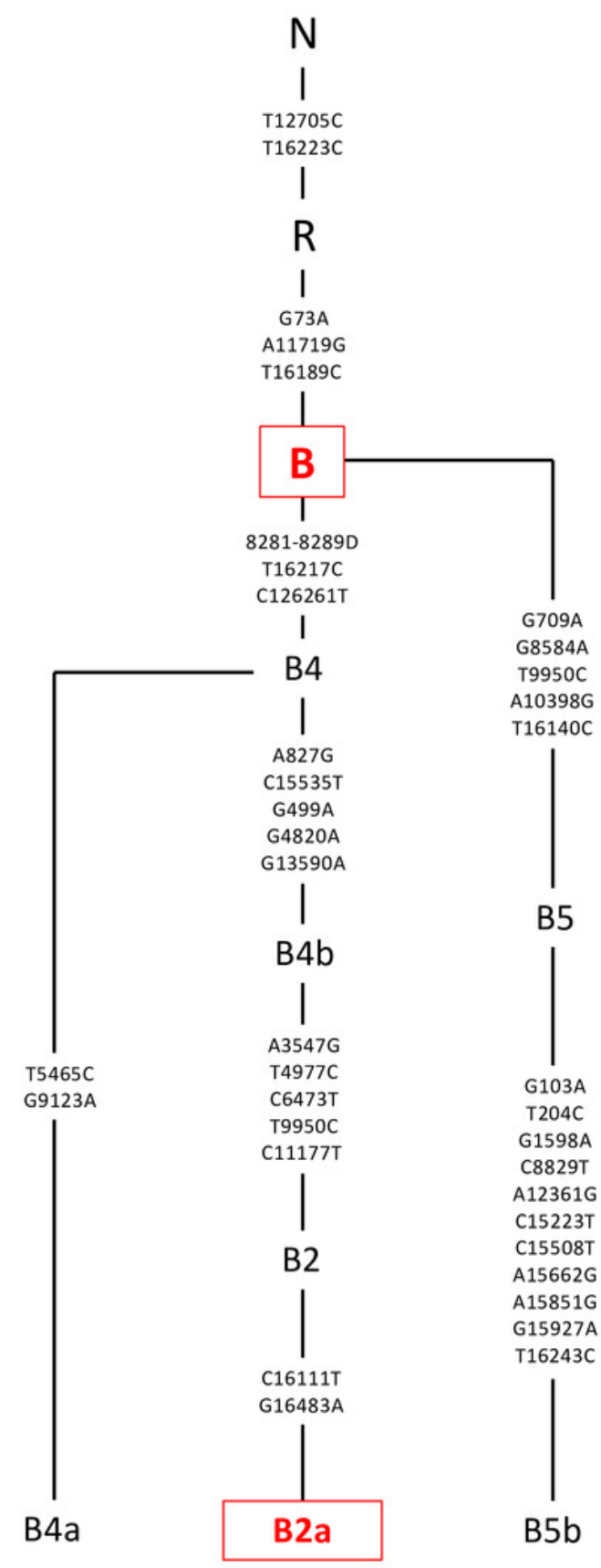




\section{Figure 4}

Mitochondrial SNP variants associated with the specific D mtDNA haplogroup types used in this study.

Platelets obtained from patients were sequenced using a kit (DNeasy Blood and Tissue Kit, Qiagen, Germantown, MD), and found to be in the $D$ mtDNA haplogroup ( $n=3)$. The $D$ mtDNA haplogroup is associated with individuals from Asian maternal descent. The specific variants of those in the $D$ mtDNA haplogroup were identified and their phylogenic tree is displayed. These variants include D4a2b, D4a6, and D4d. Next Generation Sequencing (NGS) technology was used to sequence both strands of mtDNA independently in both directions. This was done to quantitate the haplogroup-defining single nucleotide polymorphisms (SNPs), private SNPs (not defining haplogroups), and low-frequency heteroplasmy SNPs across the entire mitochondrial genome. The mtDNA sequences were analyzed using HaploGrep (www.haplogrep.uibk.ac.at) to identify the mtDNA haplogroups. SNP variants were verified using www.MitoMap.com, www.Phylotree.org, and/or www.hmtvar.uniba.it 


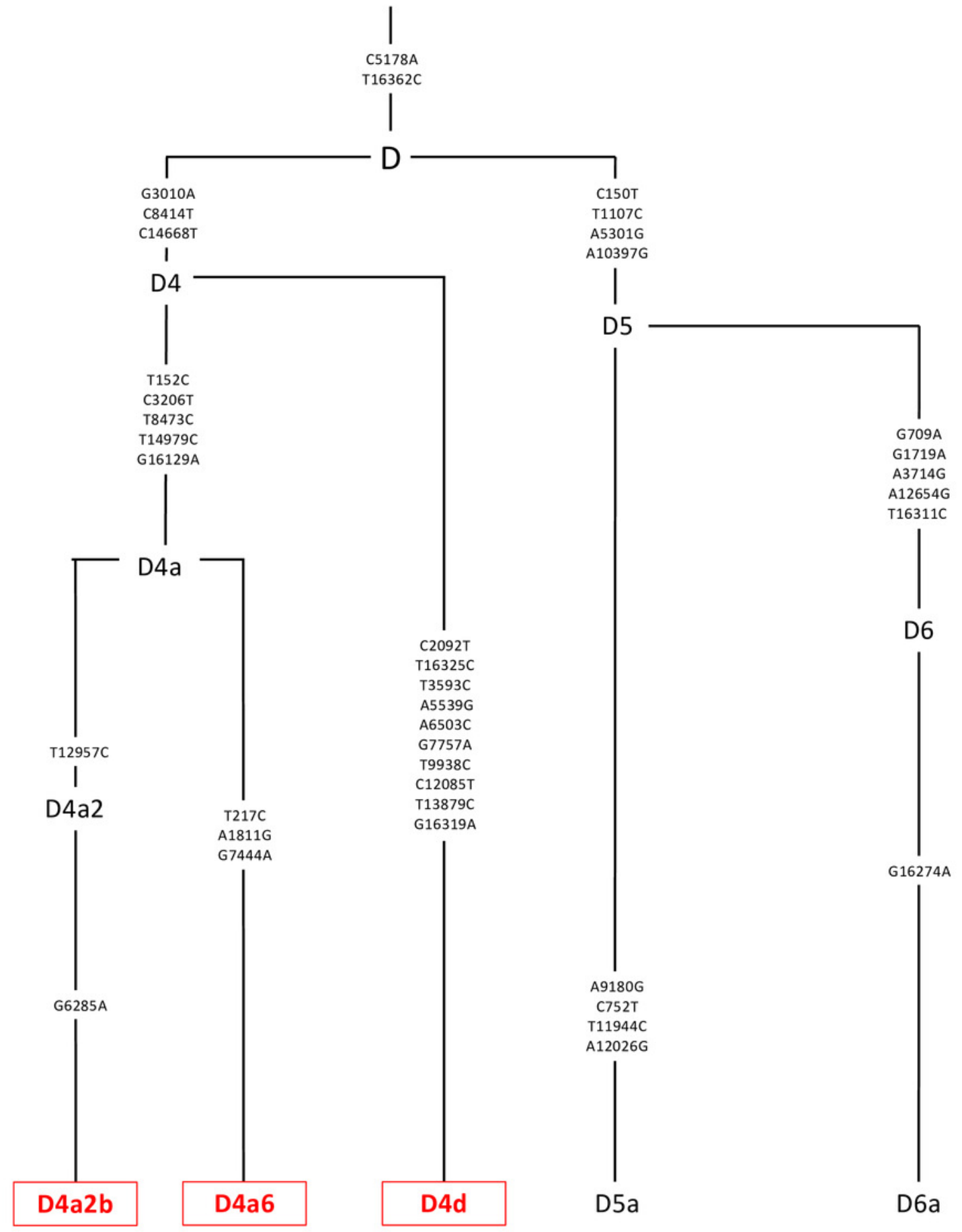




\section{Figure 5}

$L,[A+B]$, and $D$ untreated cybrids had similar cellular relative metabolic activity.

Cybrid cell lines of the fifth passage, containing mitochondria with either $L,[A+B]$, or $D$ haplogroups, were cultured in flasks until confluent. They were then plated on a 96-well plate with each well containing 50,000 cells and incubated at $37^{\circ} \mathrm{C}$ for another 48 hours. The MTT assay was then conducted to assess relative cellular metabolic activity. Absorbance was measured on an absorbance reader at $570 \mathrm{~nm}$ (measured) and $630 \mathrm{~nm}$ (reference). Cybrids had statistically similar relative cellular metabolic activities. (A) All values were normalized to the average of the untreated-L cybrids and displayed as the mean \pm Standard Error Margin (SEM). (B) The distribution of each value was also presented in a dot-plot graph representing mean \pm Standard Deviation (SD). The untreated-L cybrids $(102.4 \% \pm 7.0 \% \mathrm{SEM} ; \mathrm{SD}=21.0 \%$, $n=7$ ) had similar relative cellular metabolic activity when compared to the untreated-D cybrids $(111.7 \% \pm 4.3 \% \mathrm{SEM} ; \mathrm{SD}=11.3 \%, \mathrm{n}=3, \mathrm{p}=0.311)$ and the untreated-[A+B] cybrids $(95.0 \% \pm 8.5 \% \mathrm{SEM} ; \mathrm{SD}=20.9 \%, n=4, p=0.512)$. Untreated-[A+B] cybrids showed similar cellular metabolic activity compared to the untreated-D cybrids $(p=0.0933)$.

Experiments were analyzed in quadruplicate, and the entire experiment was repeated twice. $* p<0.05 ; * * p<0.01 ; * * * p 0.001$ 
A

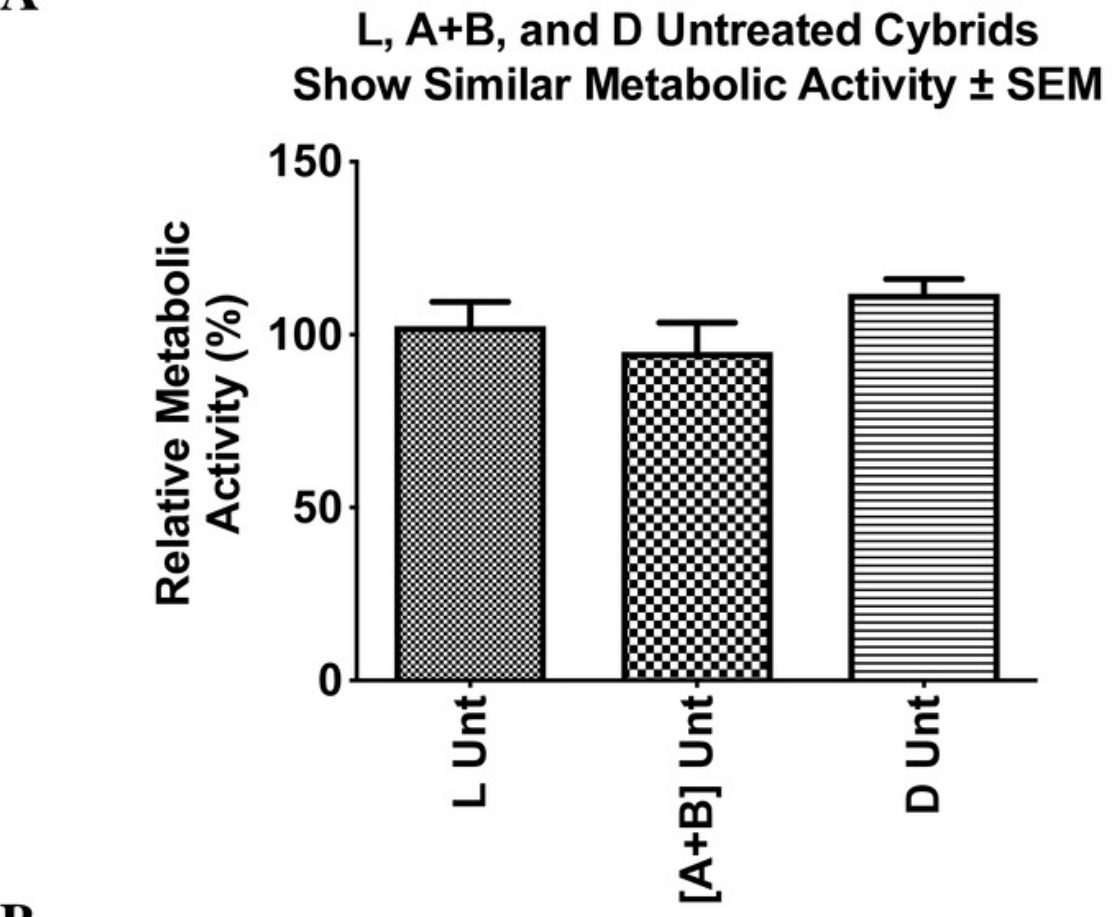

B

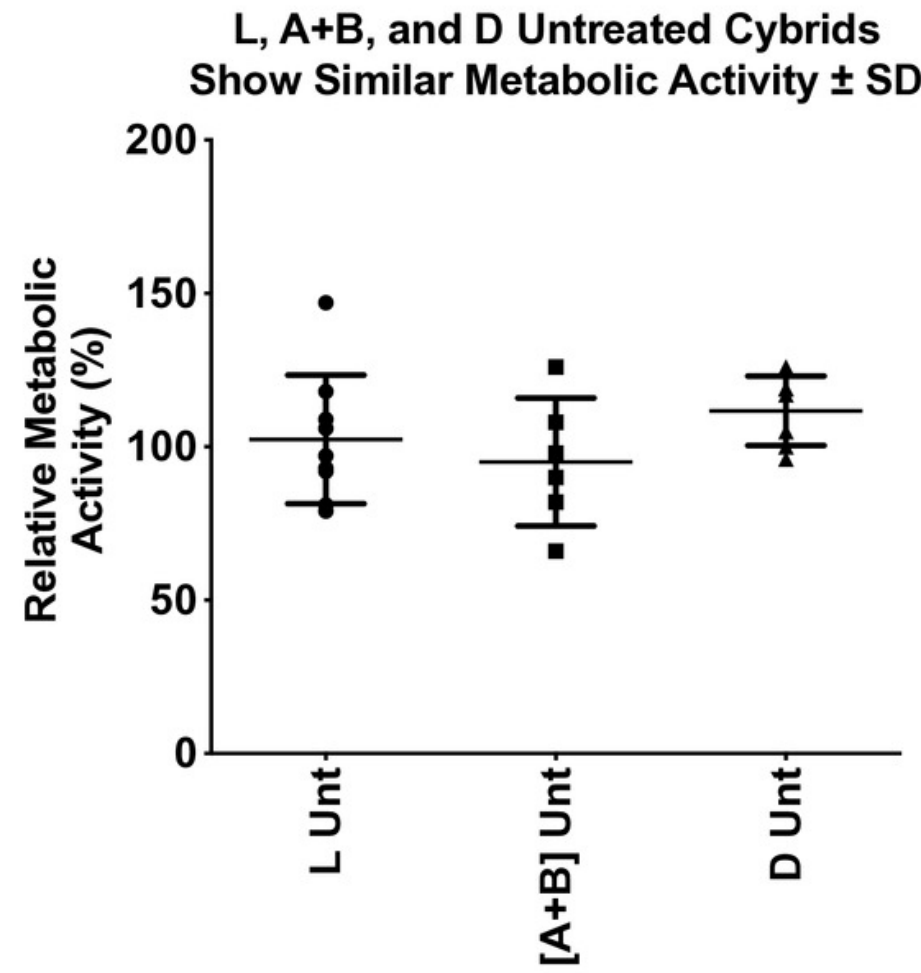




\section{Figure 6}

$L,[A+B]$, and $D$ cybrids vary in relative cellular metabolic activity after cisplatin treatment.

$L,[A+B]$, and $D$ cybrids in the fifth passage were cultured and then plated on 96-well plates with each well containing 50,000 cells. After 24 hours, media were removed, and cells were treated with $100 \mu \mathrm{L}$ of $40 \mu \mathrm{M}$ concentration of cisplatin. Plates were then incubated at $37^{\circ} \mathrm{C}$ for another 48 hours. The MTT assay was conducted to assess relative cellular metabolic activity. Absorbance values were measured on an absorbance reader at $570 \mathrm{~nm}$ (measured) and $630 \mathrm{~nm}$ (reference). (A) All values were normalized to the average of the untreated-L cybrids and displayed as the mean \pm Standard Error Margin (SEM). (B) The distribution of each value was also presented in a dot-plot graph representing mean \pm Standard Deviation (SD). The cisplatin-treated-L cybrids showed the greatest reduction in relative cellular metabolic activity compared to the untreated-L cybrids $(75.0 \% \pm 6.7 \%$ SEM; SD $=20.0 \%, n$ $=7 ; 102.4 \% \pm 7.0 \% \mathrm{SEM} ; \mathrm{SD}=21.0 \%, n=7$, respectively $(p=0.0117)$. The cisplatintreated-D cybrids showed a significant decrease in cell viability compared to the untreated-D cybrids $(86.9 \% \pm 1.6 \% \mathrm{SEM} ; \mathrm{SD}=4.3 \%, \mathrm{n}=3 ; 111.7 \% \pm 4.3 \% \mathrm{SEM} ; \mathrm{SD}=11.3 \%, \mathrm{n}=3$, respectively) $(p=0.0001)$. The cisplatin-treated-[A+B] cybrids also had a statistically significant decrease in cellular metabolic activity compared to their respective untreated$[\mathrm{A}+\mathrm{B}]$ cybrids $(70.3 \% \pm 4.5 \% \mathrm{SEM} ; \mathrm{SD}=11.1 \%, \mathrm{n}=4 ; 95.0 \% \pm 8.5 \% \mathrm{SEM} ; \mathrm{SD}=20.9 \%, \mathrm{n}=$ 4 , respectively) $(p=0.0285)$. Each treatment was run in quadruplicate and the entire experiment was repeated twice. ${ }^{*} p<0.05 ;{ }^{* *} p<0.01 ;{ }^{* * *} p<0.001$. 
A

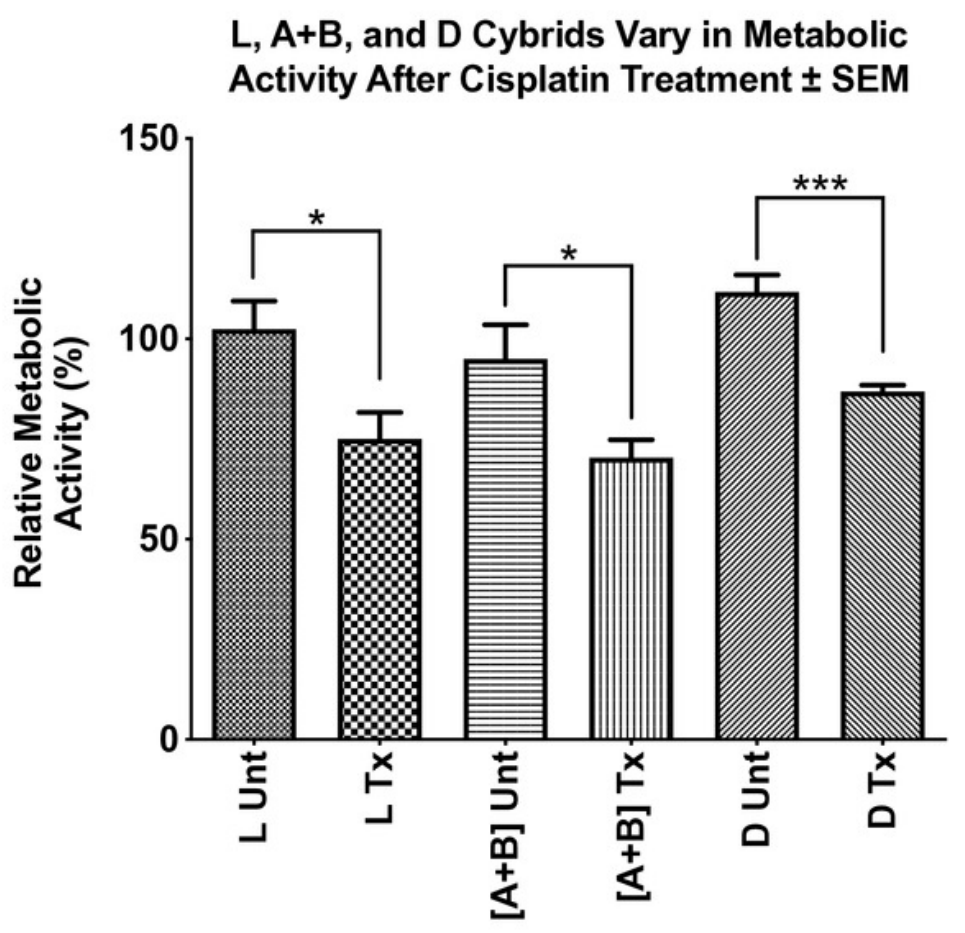

B

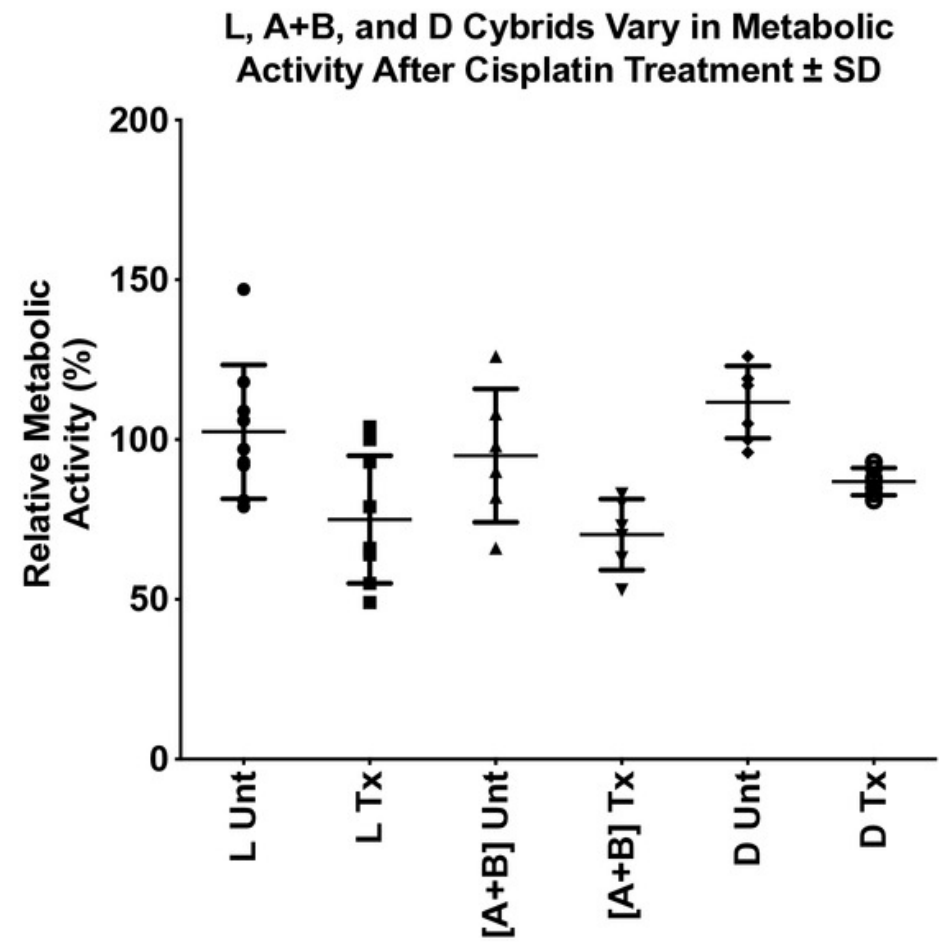




\section{Figure 7}

$L,[A+B]$, and $D$ cybrids maintained mitochondrial membrane potential $(\Delta \Psi \mathrm{m})$ after cisplatin treatment.

Mitochondrial Membrane Potentials for untreated and treated cybrid cells were measured. Mitochondrial Membrane Potentials for untreated and treated cybrid cells were measured. L, $[A+B]$, and $D$ cybrids were cultured to the fifth passage and then plated in 24-well plates $(100,000$ cells/well), incubated 24 hours and treated with 0 or $40 \mu \mathrm{M}$ of cisplatin for another 48 hours. The JC-1 assay was conducted and fluorescence values were obtained using a microplate reader. All values were normalized to the average of the untreated-L cybrids. (A) All values were normalized to the average of the untreated-L cybrids and displayed as the mean \pm Standard Error Margin (SEM). (B) The distribution of each value was also presented in a dot-plot graph representing mean \pm Standard Deviation (SD). Results indicated that there was no significant difference in mitochondrial membrane potential after cisplatin treatment in $L,[A+B]$, or $D$ cybrids. Cisplatin-treated-L cybrids had a relative mitochondrial membrane potential of $108.4 \% \pm 8.2 \% \mathrm{SEM} ; \mathrm{SD}=21.8 \%$ versus untreated-L cybrids $(101.0 \%$ $\pm 11.2 \%$ SEM; SD $=29.5 \%, n=7, p=0.602$ ). Cisplatin-treated-[A+B] displayed $136.5 \% \pm$ $33.9 \% \mathrm{SEM} ; \mathrm{SD}=67.8 \%$ versus untreated-[A+B] cybrids $(147.5 \% \pm 42.0 \% \mathrm{SEM} ; \mathrm{SD}=84.0 \%$, $n=4, p=0.845)$. The cisplatin-treated-D cybrids were observed to have a relative mitochondrial membrane potential of $115.0 \% \pm 3.5 \% \mathrm{SEM} ; \mathrm{SD}=7.0 \%$ versus the untreatedD cybrids $(127.3 \% \pm 20.1 \%$ SEM; SD $=40.3 \%, n=4, p=0.571)$ (Fig. 7A). Each treatment was run in quadruplicate and the entire experiment was repeated twice. $p<0.05$; ${ }^{* *} p<$ $0.01 ; * * * p<0.001$. 
A

\section{L, A+B, and D Cybrids Maintain Mitochondrial Membrane}

Potential $(\Delta \psi \mathrm{m})$ After Cisplatin Treatment \pm SEM

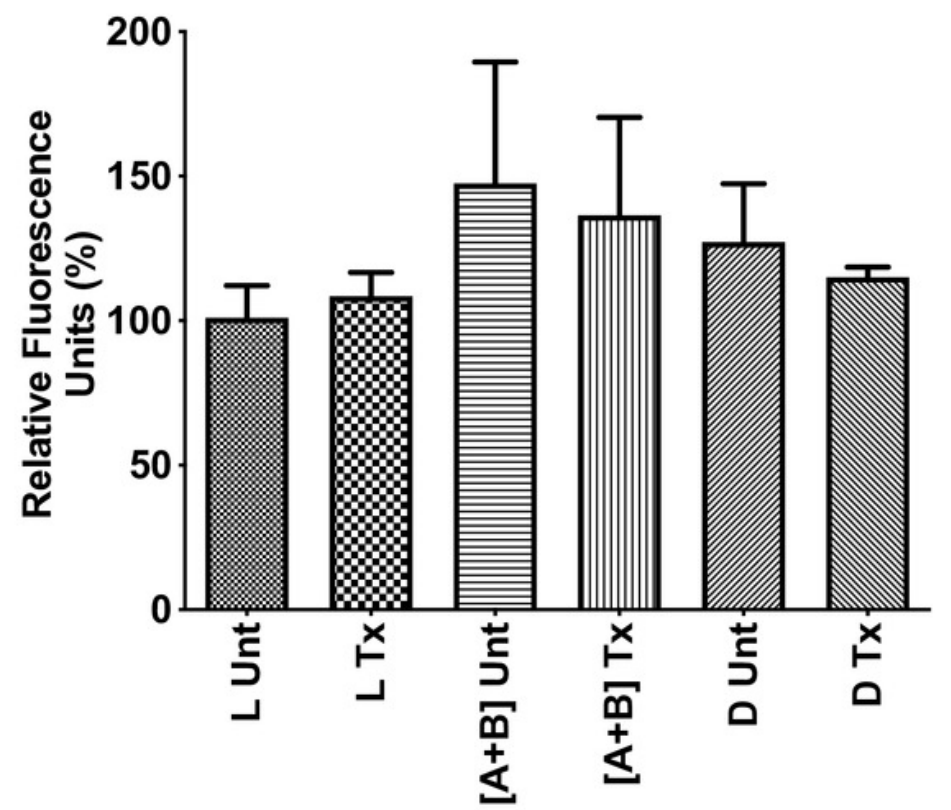

B

JC-1 scatter Mean+SEM

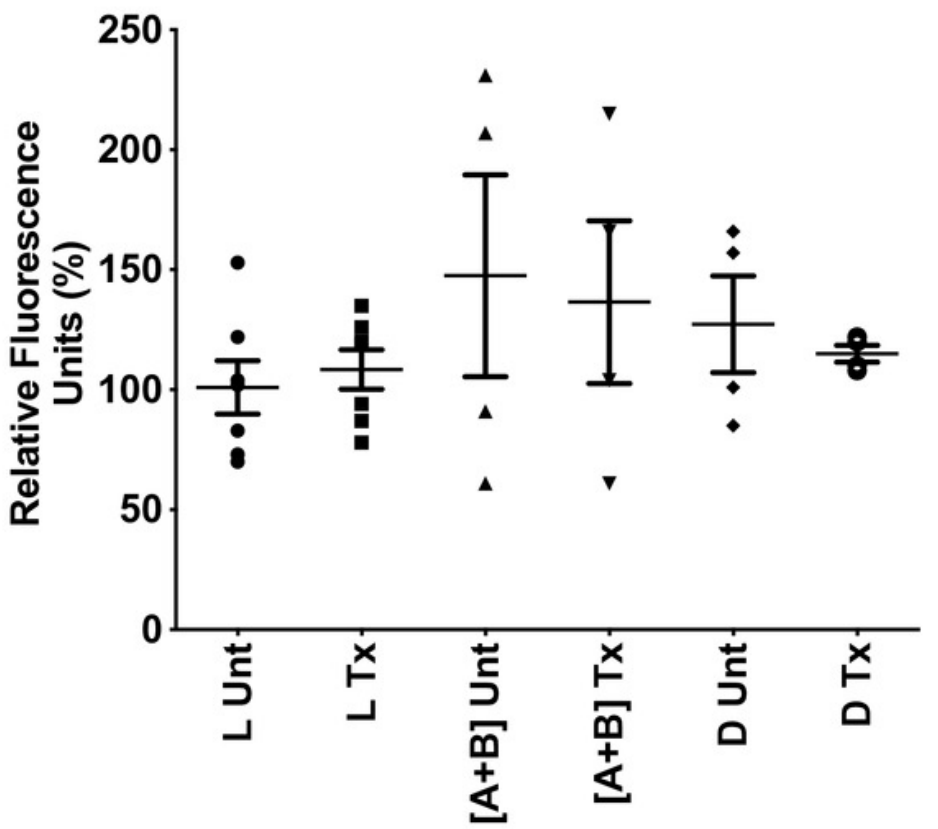




\section{Figure 8}

ARPE-19 Cells maintained mitochondrial membrane potential $\left(\Delta \Psi_{\mathrm{m}}\right)$ after cisplatin treatment (Incucyte ${ }^{\circledR}$ Live Cell Analyzer).

After cisplatin treatment, the cybrids showed decreased metabolic activity but the mitochondrial membrane potentials remained unchanged, which was unexpected. Therefore, we conducted additional experiments using the ARPE-19 cell line that allowed for comparison of growth/proliferation over 40 hours in cultures treated with $20 \mu \mathrm{M}$ or $40 \mu \mathrm{M}$ cisplatin ( $n=7$ per treatment condition). The mitochondrial membrane potential was measured with the JC-1 reagent that was added to cultures for 15 minutes. Fluorescence was measured for red and green wavelengths using a microplate reader. (A) All values were displayed as the mean \pm SD. Over the first 8 hours of culture, the untreated and cisplatin-treated ARPE-19 cells showed similar rates of growth. (B) By 10 hours the untreated ARPE-19 cells showed an increasing slope of growth compared to the $20 \mu \mathrm{M}$ and $40 \mu \mathrm{M}$ cultures that were stagnant in their growth. By 40 hours, the untreated had a 2-fold higher number of cells than cisplatintreated cultures. (Untreated $1969 \pm 115$ standard deviation (SD)), versus $20 \mu \mathrm{M}(1023 \pm 81$ $\mathrm{SD}, \mathrm{p}=0.0006)$ and $40 \mu \mathrm{M}(945 \pm 74 \mathrm{SD}, \mathrm{p}=0.0001)$ (At 40 hours, the $\Delta \psi_{\mathrm{m}}$ levels were similar between the untreated AREP-19 $(1.8993 \pm 0.145 \mathrm{SD})$ versus $20 \mu \mathrm{M}(2.0698 \pm 0.161$ $\mathrm{SD}, \mathrm{p}=\mathrm{NS})$ and $40 \mu \mathrm{M}(2.0520 \pm 0.162 \mathrm{SD}, \mathrm{p}=\mathrm{NS})$ cisplatin-treated ARPE-19 cultures. $\mathrm{p}<$ $0.05 ;{ }^{* *} p<0.01 ; * * * p<0.001$ 
A

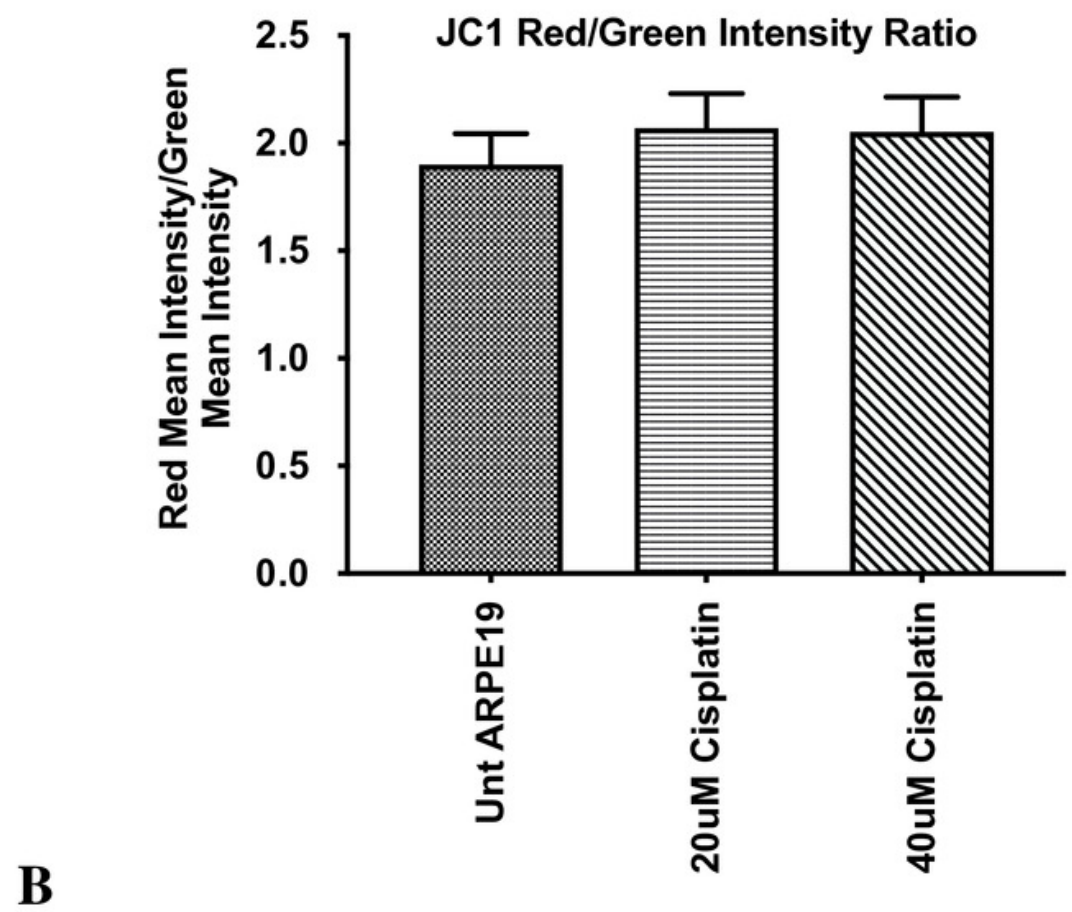

B

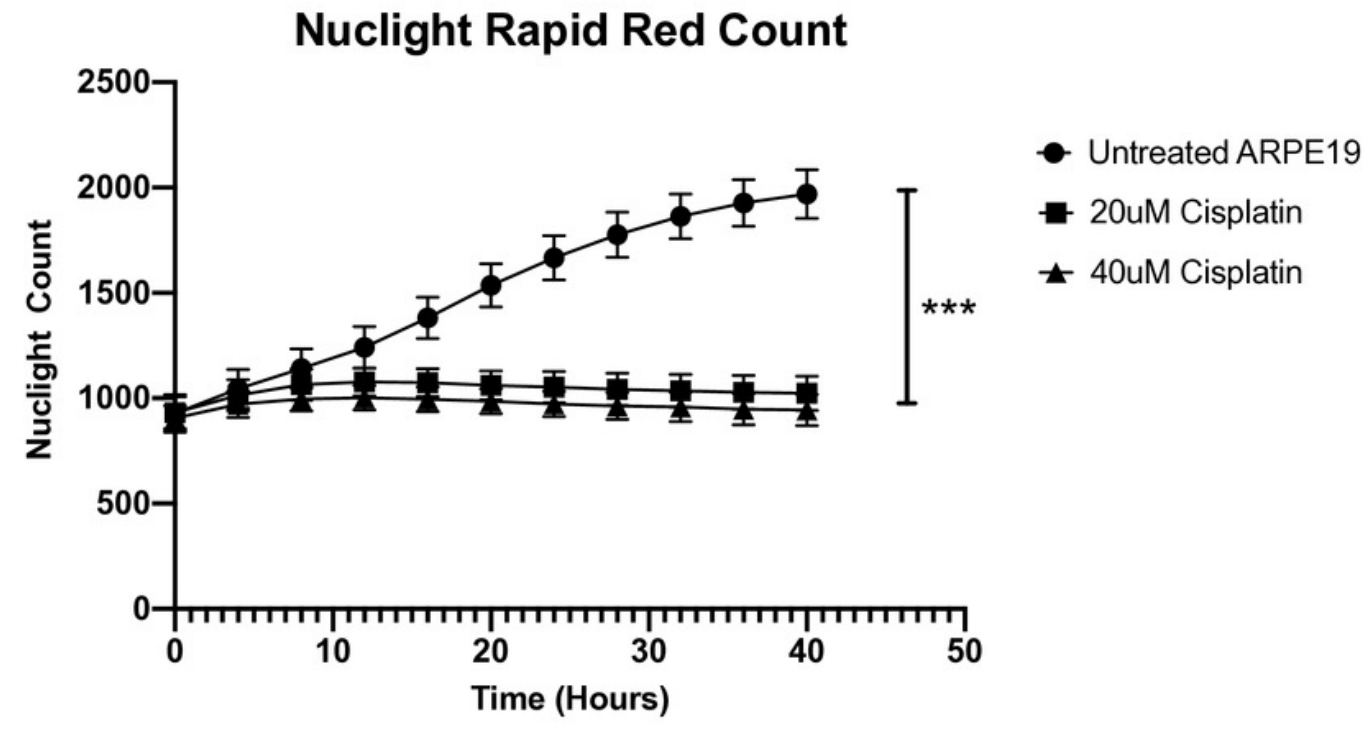




\section{Figure 9}

$L,[A+B]$, and $D$ cybrids vary in LDH cytotoxicity.

The cytotoxicity levels of $L,[A+B]$, and $D$ cybrids were measured with the lactate dehydrogenase (LDH) assay. Cybrids cultured to the fifth passage were plated in 96-well plates (10,000 cells/ well) for 24 hours and treated with 0 or $40 \mu \mathrm{M}$ of cisplatin for another 48 hours. The LDH assay was conducted and absorbance values were taken at both $490 \mathrm{~nm}$ and $680 \mathrm{~nm}$ using an absorbance reader. Percent cytotoxicity levels were calculated using the equation (Treated LDH level - spontaneous LDH level) divided by (Maximum LDH level spontaneous LDH level) multiplied by one hundred. (A) All values were normalized to the average of the untreated-L cybrids and displayed as the mean \pm Standard Error Margin (SEM). (B) The distribution of each value was also presented in a dot-plot graph representing mean \pm Standard Deviation (SD). When normalized to the $L$ cybrids, there were significantly higher LDH cytotoxicity levels in L cybrids compared to $[A+B]$ cybrids $(111.5 \% \pm 16.5 \%$ SEM; $\mathrm{SD}=40.5 \%, \mathrm{n}=6$ versus $41.8 \% \pm 9.8 \% \mathrm{SEM} ; \mathrm{SD}=16.9 \%, \mathrm{n}=3$, respectively) $(\mathrm{p}=$ 0.0270). The $D$ cybrids trended lower LDH levels but they were not significant $(48.9 \% \pm$ $20.2 \%$ SEM; SD $=35.0 \%, n=3, p=0.0576)$ compared to the L cybrids. LDH cytotoxicity levels between the $[A+B]$ and $D$ cybrids were not statistically different $(p=0.766)$. The entire experiment was repeated three separate times. ${ }^{*} p<0.05 ; * * p<0.01 ; * * p<0.001$. 
A

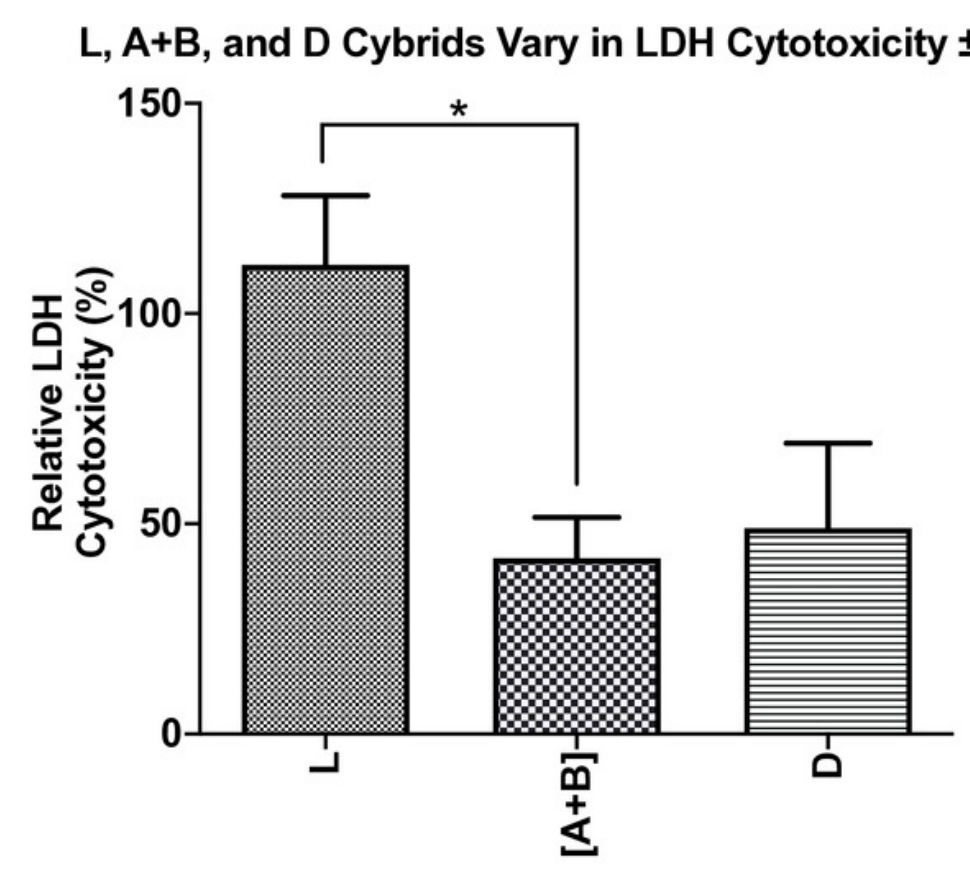

B

L, A+B, and D Cybrids Vary in LDH Cytotoxicity \pm SD

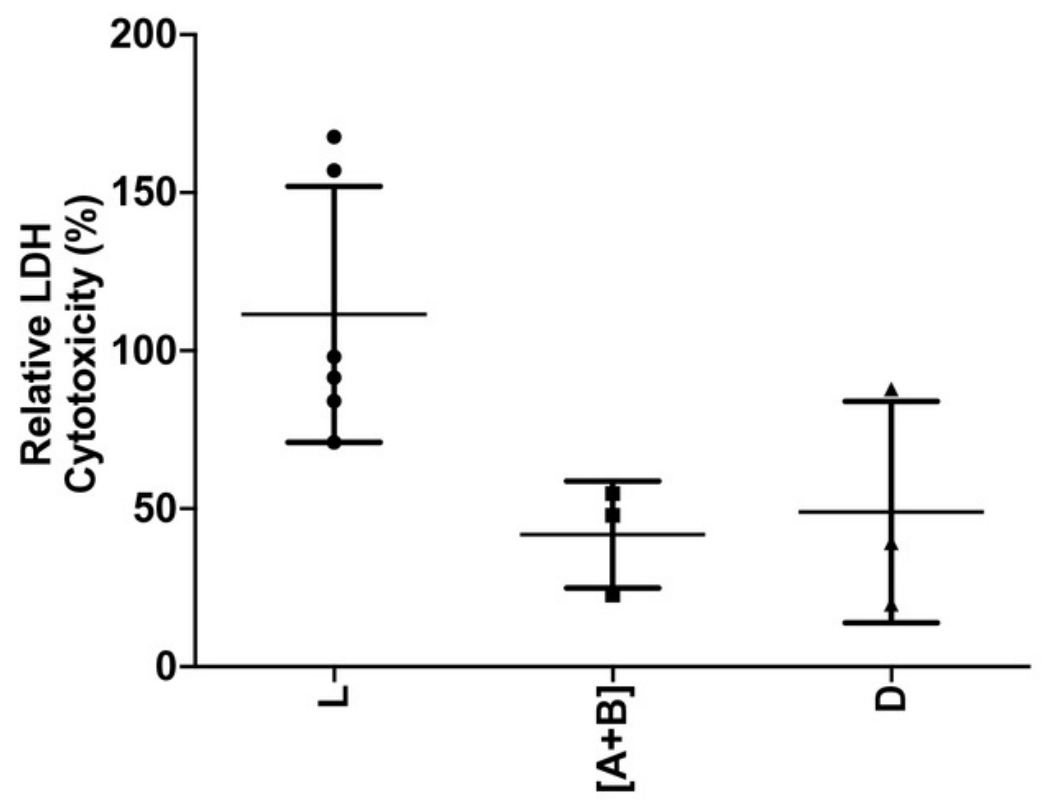




\section{Table $\mathbf{1}$ (on next page)}

Haplogroup profiles for the ARPE-19 cybrids.

Illustration of cybrid cell lines used with their associated haplogroup type along with the age and gender of the respective donor. Cytoplasmic hybrids (cybrids), cell lines with identical nuclear genomes but different mitochondrial genomes, were created and used in the fifth passage for all experiments. Cybrid cells were created using platelets isolated from peripheral blood that was fused with Rho0 (mtDNA free) ARPE-19 cells. The mtDNA haplogroups for each subject and cybrid cell line were identified using polymerase chain reaction (PCR) along with restriction enzyme digestion and mtDNA sequencing. DNA was extracted from the individual cybrids ( $n=7$ for $L$ cybrids, $n=4$ for $[A+B]$ cybrids, and $n=3$ for D cybrids) using a kit. Next Generation Sequencing (NGS) technology was used to sequence both strands of mtDNA independently in both directions. This was done to quantitate the haplogroup-defining single nucleotide polymorphisms (SNPs), private SNPS (not defining haplogroups), and low-frequency heteroplasmy SNPs across the entire mitochondrial genome. All of the SNPs identified had a Quality Score of 100 and Passed all of the Filters. 


\begin{tabular}{|l|l|l|l|}
\hline Subject & Haplogroup & Age & Gender \\
\hline Cyb L 11-38 & L0a1a1 & 38 & F \\
\hline Cyb L 11-30 & L1b1a & 54 & F \\
\hline Cyb L 13-126 & L1b1a7 & 39 & F \\
\hline Cyb L 13-124 & L1b2a & 31 & M \\
\hline Cyb L 13-125 & L1c2a1 & 52 & F \\
\hline Cyb L 11-31 & L2b2 & 42 & M \\
\hline Cyb L 11-17 & L3e1a1a & 64 & F \\
\hline & & & \\
\hline Cyb A 11-16 & A2 & 42 & F \\
\hline Cyb A 11-14 & A2w & 34 & F \\
\hline & & 35 & \\
\hline Cyb B 12-40 & B & 31 & M \\
\hline Cyb B 13-68 & B2a & 45 & F \\
\hline Cyb D 13-55 & D4a2b & 39 & F \\
\hline Cyb D 11-18 & D4a6 & D4d & M \\
\hline Cyb D 11-29 & & 37 & \\
\hline
\end{tabular}




\section{Table 2 (on next page)}

$L, A+B$, and D mtDNA haplogroup ARPE-19 cybrids displayed unique SNP variants.

SNP Variants associated with the $L,[A+B]$, and $D$ mtDNA haplogroups were compared to one another. Nucleotide changes containing one or more differences between the studied haplogroups were identified and analyzed. The location of the nucleotide change within the mtDNA, the base pair changed, their associated rs number, their presence in the $L,[A+B]$, or D cybrids, and any associated pathogenesis found in the literature were identified and displayed. Non-synonymous changes present in some but not all haplogroups tested were found at 4824 A>G, rs ND; 5178 C>A, rs28357984; 5442 T>C, rs3020601; 7146 G>A, rs372136420; 8701 G>A, rs2000975; 8794 C>T , rs2298007; 10398 G>A, rs2853826; and 13105 G>A, rs2853501. Data was incorporated using www.hmtvar.uniba.it as well as www. phylotree.org. 
2

\begin{tabular}{|c|c|c|c|c|c|c|c|}
\hline $\begin{array}{l}\text { Loci: } \\
\text { MT- }\end{array}$ & SNP & AA Change & rs\# & $\begin{array}{l}\text { Present } \\
\text { in } L \\
\text { Cybrids }\end{array}$ & $\begin{array}{l}\text { Present } \\
\text { in } A+B \\
\text { Cybrids }\end{array}$ & $\begin{array}{l}\text { Present } \\
\text { in D } \\
\text { Cybrids }\end{array}$ & $\begin{array}{c}\text { Related } \\
\text { Pathogenesis }\end{array}$ \\
\hline $\begin{array}{l}\text { D- } \\
\text { Loop }\end{array}$ & $\begin{array}{l}152 \\
\mathrm{C}>\mathrm{T}\end{array}$ & Noncoding & rs117135796 & No & Yes & Yes & $\begin{array}{l}\text { Predisposition to } \\
\text { ataxia, bladder } \\
\text { cancer, aging, } \\
\text { hepatocellular } \\
\text { carcinoma, } \\
\text { predisposition to } \\
\text { breast cancer, lung } \\
\text { cancer, } \\
\text { nasopharyngeal } \\
\text { carcinoma, stomach } \\
\text { cancer, liver cancer, } \\
\text { ovarian carcinoma }\end{array}$ \\
\hline $\begin{array}{l}\text { D- } \\
\text { Loop }\end{array}$ & $\begin{array}{c}182 \\
\mathrm{~T}>\mathrm{C}\end{array}$ & Noncoding & rs41473347 & No & Yes & Yes & $\begin{array}{l}\text { Predisposition to } \\
\text { ataxia, bladder } \\
\text { cancer, lung cancer }\end{array}$ \\
\hline $\begin{array}{l}\text { D- } \\
\text { Loop }\end{array}$ & $\begin{array}{l}195 \\
\mathrm{C}>\mathrm{T}\end{array}$ & Noncoding & rs 2857291 & No & Yes & Yes & $\begin{array}{l}\text { Bipolar disease, } \\
\text { predisposition to } \\
\text { ataxia, bladder } \\
\text { cancer, aging, breast } \\
\text { cancer, lung cancer }\end{array}$ \\
\hline $\begin{array}{l}\text { D- } \\
\text { Loop }\end{array}$ & $\begin{array}{c}235 \\
A>G\end{array}$ & Noncoding & rs3937037 & No & Yes & No & Lung cancer \\
\hline $\begin{array}{c}\text { D- } \\
\text { Loop }\end{array}$ & $\begin{array}{c}247 \\
\mathrm{~A}>\mathrm{G}\end{array}$ & Noncoding & rs41334645 & No & Yes & Yes & $\begin{array}{l}\text { Predisposition to } \\
\text { ataxia }\end{array}$ \\
\hline $\begin{array}{l}\text { D- } \\
\text { Loop }\end{array}$ & $\begin{array}{r}263 \\
G>A\end{array}$ & Noncoding & rs 2853515 & Yes & No & No & $\begin{array}{l}\text { Oncocytic adenomas, } \\
\text { predisposition to } \\
\text { ataxia, breast cancer, } \\
\text { nasopharyngeal } \\
\text { carcinoma }\end{array}$ \\
\hline RNR1 & $\begin{array}{c}663 \\
A>G\end{array}$ & rRNA & ND & No & Yes & No & Hearing loss \\
\hline RNR1 & $\begin{array}{c}769 \\
A>G\end{array}$ & rRNA & rs 2853519 & No & Yes & Yes & N/A \\
\hline RNR1 & $\begin{array}{l}825 \\
\mathrm{~A}>\mathrm{T}\end{array}$ & rRNA & rs 2853520 & No & Yes & Yes & N/A \\
\hline RNR1 & $\begin{array}{l}1018 \\
A>G\end{array}$ & rRNA & rs 2856982 & No & Yes & Yes & $\begin{array}{c}\text { Heteroplasmic } \\
\text { variant }\end{array}$ \\
\hline RNR1 & $\begin{array}{l}1048 \\
\mathrm{C}>\mathrm{T}\end{array}$ & rRNA & rs2000974 & Yes & No & No & $\begin{array}{c}\text { Heteroplasmic } \\
\text { variant, hearing loss }\end{array}$ \\
\hline
\end{tabular}




\begin{tabular}{|c|c|c|c|c|c|c|c|}
\hline RNR2 & $\begin{array}{l}1736 \\
A>G\end{array}$ & rRNA & rs193303006 & No & Yes & No & $\begin{array}{c}\text { Heteroplasmic } \\
\text { variant }\end{array}$ \\
\hline RNR2 & $\begin{array}{l}2758 \\
A>G\end{array}$ & rRNA & rs 2856980 & No & Yes & Yes & N/A \\
\hline RNR2 & $\begin{array}{l}2885 \\
\mathrm{C}>\mathrm{T}\end{array}$ & rRNA & rs 2854130 & No & Yes & Yes & $\mathrm{N} / \mathrm{A}$ \\
\hline ND1 & $\begin{array}{l}3516 \\
C>A\end{array}$ & syn:L-L & rs2854132 & Yes & No & No & N/A \\
\hline ND1 & $\begin{array}{l}3594 \\
\mathrm{~T}>\mathrm{C}\end{array}$ & syn:V-V & rs 193303025 & No & Yes & Yes & Thyroid tumor \\
\hline ND1 & $\begin{array}{l}4104 \\
G>A\end{array}$ & syn:L-L & rs1117205 & No & Yes & Yes & $\mathrm{N} / \mathrm{A}$ \\
\hline ND1 & $\begin{array}{l}4248 \\
\mathrm{~T}>\mathrm{C}\end{array}$ & syn:I-I & rs9326618 & No & Yes & No & Homoplasmic variant \\
\hline ND2 & $\begin{array}{l}4824 \\
A>G\end{array}$ & $\begin{array}{c}\text { non-syn:T- } \\
\text { A }\end{array}$ & ND & No & Yes & No & Glaucoma \\
\hline ND2 & $\begin{array}{l}5178 \\
\mathrm{C}>\mathrm{A}\end{array}$ & $\begin{array}{c}\text { non-syn:L- } \\
\text { M }\end{array}$ & rs28357984 & No & No & Yes & $\begin{array}{l}\text { Infertility, increased } \\
\text { longevity, diabetes, } \\
\text { atherosclerosis, } \\
\text { hypertension, } \\
\text { myocardial } \\
\text { infarction, } \\
\text { Parkinson's disease, } \\
\text { glaucoma, blood iron } \\
\text { metabolism, and } \\
\text { cardiovascular } \\
\text { disease }\end{array}$ \\
\hline ND2 & $\begin{array}{l}5442 \\
\mathrm{~T}>\mathrm{C}\end{array}$ & $\begin{array}{c}\text { non-syn:F- } \\
\text { L }\end{array}$ & rs3020601 & Yes & No & No & $\begin{array}{l}\text { Risk of mobility } \\
\text { impairment }\end{array}$ \\
\hline $\mathrm{CO} 1$ & $\begin{array}{l}6185 \\
\mathrm{~T}>\mathrm{C}\end{array}$ & syn:F-F & rs1029272 & Yes & No & No & $\begin{array}{c}\text { Primary Open-Angle } \\
\text { Glaucoma (POAG) }\end{array}$ \\
\hline $\mathrm{CO} 1$ & $\begin{array}{l}7146 \\
\mathrm{G}>\mathrm{A}\end{array}$ & $\begin{array}{c}\text { non-syn:T- } \\
\text { A }\end{array}$ & rs372136420 & No & Yes & Yes & Asthenospermia \\
\hline $\mathrm{CO} 1$ & $\begin{array}{l}7256 \\
\mathrm{~T}>\mathrm{C}\end{array}$ & syn:N-N & ND & No & Yes & Yes & $\mathrm{N} / \mathrm{A}$ \\
\hline $\mathrm{TD}$ & $\begin{array}{l}7521 \\
A>G\end{array}$ & tRNA & rs200336937 & No & Yes & Yes & $\begin{array}{l}\text { Thyroid cancer, } \\
\text { colorectal tumor }\end{array}$ \\
\hline ATP8 & $\begin{array}{l}8468 \\
\mathrm{~T}>\mathrm{C}\end{array}$ & syn:L-L & rs1116907 & No & Yes & Yes & N/A \\
\hline ATP6 & $\begin{array}{l}8655 \\
\mathrm{~T}>\mathrm{C}\end{array}$ & syn:I-I & rs2853822 & No & Yes & Yes & N/A \\
\hline ATP6 & $\begin{array}{l}8701 \\
\mathrm{G}>\mathrm{A}\end{array}$ & $\begin{array}{c}\text { non-syn:T- } \\
\text { A }\end{array}$ & rs2000975 & No & Yes & No & $\begin{array}{c}\text { Neuromuscular } \\
\text { disorders, somatic } \\
\text { lung cancer, thyroid } \\
\text { cancer, fertilization }\end{array}$ \\
\hline
\end{tabular}




\begin{tabular}{|c|c|c|c|c|c|c|c|}
\hline & & & & & & & $\begin{array}{c}\text { failure, } \\
\text { atherosclerosis, } \\
\text { irritable bowel } \\
\text { syndrome, } \\
\text { osteosarcoma, } \\
\text { MELAS, } \\
\text { cardiomyopathy, } \\
\text { Parkinson disease, } \\
\text { hearing loss }\end{array}$ \\
\hline ATP6 & $\begin{array}{l}8794 \\
\mathrm{C}>\mathrm{T}\end{array}$ & $\begin{array}{c}\text { non-syn:H- } \\
\text { Y }\end{array}$ & rs2298007 & No & Yes & No & $\begin{array}{l}\text { Homoplasmic } \\
\text { variant, coronary } \\
\text { arteriosclerosis, } \\
\text { irritable bowel } \\
\text { syndrome }\end{array}$ \\
\hline ATP6 & $\begin{array}{l}9042 \\
\mathrm{C}>\mathrm{T}\end{array}$ & syn:H-H & rs3020605 & Yes & No & No & Homoplasmic variant \\
\hline $\mathrm{CO} 3$ & $\begin{array}{l}9347 \\
A>G\end{array}$ & syn:L-L & rs 2853824 & Yes & No & No & Homoplasmic variant \\
\hline $\mathrm{CO} 3$ & $\begin{array}{l}9540 \\
\mathrm{C}>\mathrm{T}\end{array}$ & syn:L-L & rs 2248727 & No & Yes & No & $\begin{array}{l}\text { Normal-Tension } \\
\text { Glaucoma (NTG) }\end{array}$ \\
\hline ND3 & $\begin{array}{c}10398 \\
G>A\end{array}$ & $\begin{array}{c}\text { non-syn:T- } \\
\text { A }\end{array}$ & rs 2853826 & No & Yes & No & $\begin{array}{l}\text { IVF failure, Fuch's } \\
\text { Endothelial Corneal } \\
\text { Dystrophy (FECD), } \\
\text { breast cancer, } \\
\text { esophageal cancer, } \\
\text { aging, diabetes, } \\
\text { osteoarthritis, } \\
\text { schizophrenia, LHON }\end{array}$ \\
\hline ND4L & $\begin{array}{c}10589 \\
\mathrm{G}>\mathrm{A}\end{array}$ & syn:L-L & rs 2853487 & Yes & No & No & Homoplasmic variant \\
\hline ND4L & $\begin{array}{c}10688 \\
A>G\end{array}$ & syn:V-V & rs 2853488 & No & Yes & Yes & N/A \\
\hline ND4 & $\begin{array}{c}10810 \\
\mathrm{C}>\mathrm{T}\end{array}$ & syn:L-L & rs 28358282 & No & Yes & Yes & N/A \\
\hline ND4 & $\begin{array}{c}10873 \\
\mathrm{C}>\mathrm{T}\end{array}$ & syn:P-P & rs 2857284 & No & Yes & No & Ischemic stroke \\
\hline ND4 & $\begin{array}{c}12007 \\
\mathrm{G}>\mathrm{A}\end{array}$ & syn:W-W & rs2853497 & Yes & No & No & Homoplasmic variant \\
\hline ND5 & $\begin{array}{c}12705 \\
\mathrm{~T}>\mathrm{C}\end{array}$ & syn:I-I & rs193302956 & No & Yes & No & $\begin{array}{c}\text { Neuropathy, } \\
\text { dystonia, myoclonic } \\
\text { epilepsy, MERRF, } \\
\text { PD, schizophrenia, } \\
\text { bipolar disorder, } \\
\text { infantile } \\
\text { cardiomyopathy, } \\
\text { diabetes, } \\
\text { hypertension, AD, }\end{array}$ \\
\hline
\end{tabular}




\begin{tabular}{|c|c|c|c|c|c|c|c|}
\hline & & & & & & & $\begin{array}{c}\text { Leigh syndrome, } \\
\text { blood pressure }\end{array}$ \\
\hline ND5 & $\begin{array}{c}12720 \\
A>G\end{array}$ & syn:M-M & rs 2853500 & Yes & No & No & Homoplasmic variant \\
\hline ND5 & $\begin{array}{c}13105 \\
G>A\end{array}$ & $\begin{array}{c}\text { non-syn:I- } \\
\text { V }\end{array}$ & s2853501 & No & Yes & Yes & Deafness, neuropathy \\
\hline ND5 & $\begin{array}{c}13506 \\
T>C\end{array}$ & syn:Y-Y & rs 2857287 & No & Yes & Yes & N/A \\
\hline ND5 & $\begin{array}{c}13650 \\
\mathrm{~T}>\mathrm{C}\end{array}$ & syn:P-P & rs2854123 & No & Yes & Yes & $\mathrm{N} / \mathrm{A}$ \\
\hline CYB & $\begin{array}{c}15301 \\
A>G\end{array}$ & syn:L-L & rs193302991 & No & Yes & No & Homoplasmic variant \\
\hline CYB & $\begin{array}{c}15301 \\
\mathrm{G}>\mathrm{A}\end{array}$ & syn:L-L & rs193302991 & No & Yes & Yes & Homoplasmic variant \\
\hline $\begin{array}{l}\text { D- } \\
\text { Loop }\end{array}$ & $\begin{array}{c}16129 \\
A>G\end{array}$ & Noncoding & rs41534744 & No & Yes & Yes & $\begin{array}{l}\text { Ewing's sarcoma, } \\
\text { predisposition to } \\
\text { breast cancer, } \\
\text { nasopharyngeal } \\
\text { carcinoma }\end{array}$ \\
\hline $\begin{array}{c}\text { D- } \\
\text { Loop }\end{array}$ & $\begin{array}{c}16187 \\
\mathrm{~T}>\mathrm{C}\end{array}$ & Noncoding & ND & No & Yes & Yes & $\begin{array}{l}\text { Friedreich's ataxia, } \\
\text { bladder cancer, lung } \\
\text { cancer }\end{array}$ \\
\hline $\begin{array}{c}\text { D- } \\
\text { Loop }\end{array}$ & $\begin{array}{c}16189 \\
\mathrm{~T}>\mathrm{C}\end{array}$ & Noncoding & rs28693675 & No & Yes & No & $\begin{array}{l}\text { Diabetes mellitus, } \\
\text { insulin resistance, } \\
\text { cardiomyopathy, } \\
\text { hypertension, } \\
\text { Friedreich's } \\
\text { ataxia, Ewing's } \\
\text { sarcoma, obesity, } \\
\text { predisposition to } \\
\text { breast cancer, } \\
\text { nasopharyngeal } \\
\text { carcinoma }\end{array}$ \\
\hline $\begin{array}{c}\text { D- } \\
\text { Loop }\end{array}$ & $\begin{array}{c}16189 \\
\mathrm{C}>\mathrm{T}\end{array}$ & Noncoding & rs28693675 & No & Yes & Yes & $\begin{array}{l}\text { Diabetes mellitus, } \\
\text { insulin resistance, } \\
\text { cardiomyopathy, } \\
\text { hypertension, } \\
\text { Friedreich's ataxia, } \\
\text { Ewing's sarcoma, } \\
\text { obesity, } \\
\text { predisposition to } \\
\text { breast cancer, } \\
\text { nasopharyngeal } \\
\text { carcinoma }\end{array}$ \\
\hline $\begin{array}{c}\text { D- } \\
\text { Loop }\end{array}$ & $\begin{array}{c}16223 \\
\mathrm{~T}>\mathrm{C}\end{array}$ & Noncoding & rs 2853513 & No & Yes & No & $\begin{array}{l}\text { Mitochondrial } \\
\text { disease, } \\
\text { predisposition to }\end{array}$ \\
\hline
\end{tabular}




\begin{tabular}{|c|c|c|c|c|c|c|c|}
\hline & & & & & & & $\begin{array}{c}\text { ataxia, bladder } \\
\text { cancer, predisposition } \\
\text { to breast cancer, lung } \\
\text { cancer, } \\
\text { nasopharyngeal } \\
\text { carcinoma, stomach } \\
\text { cancer, liver cancer }\end{array}$ \\
\hline $\begin{array}{c}\text { D- } \\
\text { Loop }\end{array}$ & $\begin{array}{c}16278 \\
\mathrm{~T}>\mathrm{C}\end{array}$ & Noncoding & rs41458645 & No & Yes & Yes & $\begin{array}{l}\text { Bladder cancer, } \\
\text { predisposition to } \\
\text { breast cancer, lung } \\
\text { cancer }\end{array}$ \\
\hline $\begin{array}{c}\text { D- } \\
\text { Loop }\end{array}$ & $\begin{array}{c}16290 \\
\mathrm{C}>\mathrm{T}\end{array}$ & Noncoding & ND & No & Yes & No & Parkinson's disease \\
\hline $\begin{array}{c}\text { D- } \\
\text { Loop }\end{array}$ & $\begin{array}{c}16311 \\
\mathrm{C}>\mathrm{T}\end{array}$ & Noncoding & rs34799580 & No & Yes & Yes & $\begin{array}{l}\text { Bladder cancer, } \\
\text { predisposition to } \\
\text { breast cancer, lung } \\
\text { cancer }\end{array}$ \\
\hline $\begin{array}{c}\text { D- } \\
\text { Loop }\end{array}$ & $\begin{array}{c}16319 \\
G>A\end{array}$ & Noncoding & rs35105996 & No & Yes & No & Homoplasmic variant \\
\hline $\begin{array}{c}\text { D- } \\
\text { Loop }\end{array}$ & $\begin{array}{c}16362 \\
T>C\end{array}$ & Noncoding & rs62581341 & No & No & Yes & $\begin{array}{l}\text { Homoplasmic } \\
\text { variant, } \\
\text { mitochondrial } \\
\text { disease, bladder } \\
\text { cancer, } \\
\text { predisposition to } \\
\text { breast cancer, lung } \\
\text { cancer, stomach } \\
\text { cancer, liver cancer }\end{array}$ \\
\hline
\end{tabular}

ND, Not Determined

All SNP's had a Quality (A Phred-scaled quality score assigned by the variant caller) Score of 100 and Passed all the Filters. 


\section{Table 3 (on next page)}

$L,[A+B]$, and $D$ mtDNA haplogroup cybrids each displayed unique overall results in cell and gene expression studies.

Results from the cell and gene expression studies were congregated into one table. As illustrated, each haplogroup had a unique result when observed in large as a summation of the assays and gene expression results. As demonstrated from the cell and gene expression studies, $L$ cybrids had decreased cellular metabolic activity and $A L K$ gene expression after cisplatin treatment ( $p=0.0117, p<0.0001$ respectively). [A+B] cybrids had decreased cellular metabolic activity, $A L K$ gene expression, and $E G F R$ gene expression after cisplatin treatment $(p=0.0285, p=0.0001, p=0.0246$, respectively). $D$ cybrids had decreased cellular metabolic activity after cisplatin treatment $(p=0.0001) .{ }^{*} p<0.05 ; * * p 0.01 ; * * p$ $<0.001$. 


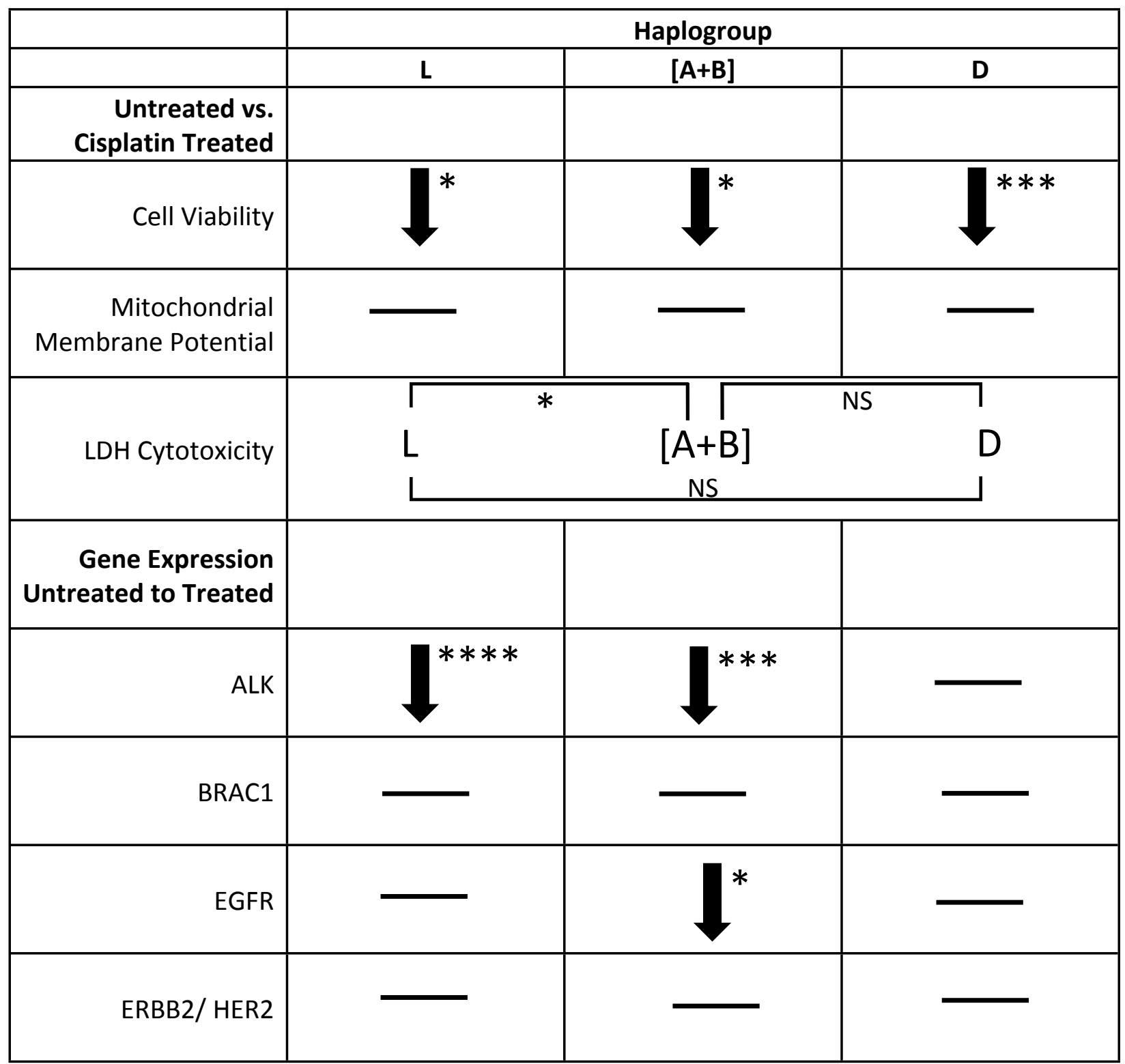




\section{Table 4(on next page)}

$L,[A+B]$, and $D$ mtDNA haplogroup cybrids had varying gene expression values after treatment with cisplatin.

Gene expression results, as well as detailed overviews forALK,BRCA1,EGFR, andERBB2/HER2genes, were summarized into one table. Gene expression values were observed with qPCR for all $L,[A+B]$, and $D$ cybrids and assessed for statistical significance relative to their untreated controls. Cybrids cultured to the fifth passage were plated in sixwell plates (500,000 cells/well) and incubated for 24 hours. Cybrids were then treated with culture media containing either 0 or $40 \mu \mathrm{M}$ of cisplatin for an additional 48 hours. RNA was isolated and qRT-PCR was conducted to analyze gene expression. Cancer-related nuclear genes were selected as they are common targets and biomarkers in chemotherapeutic treatments. Fold differences were quantified using the equation $2(\Delta \Delta \mathrm{Ct})$, and the values for each sample were normalized to that of the untreated for each haplogroup. There were significant drops in gene expression levels in the treated-L cybrids forALKgene expression $(-18.8 \% \pm 9.7 \%, p<0.0001)$, and treated-[A+B] for bothALKandEGFRgene expression levels $(-17.5 \% \pm 9.5 \%, p=0.0001 ;-49.2 \% \pm 17.1 \%, p=0.025)$. Each experiment was conducted three separate times. ${ }^{*} p<0.05 ; * * p<0.01 ; * * * p<0.001$. 


\begin{tabular}{|c|c|c|c|c|c|c|}
\hline SYMBOL & GENE NAME & $\begin{array}{c}\text { GENBANK } \\
\text { ACCESSION } \\
\text { NUMBERS }\end{array}$ & FUNCTIONS & $\begin{array}{l}\underline{\text { L Cybrids }} \\
\text { Untreated\# vs } \\
\text { Treated } \\
\text { P value, } \\
\text { Fold }\end{array}$ & $\begin{array}{c}\text { [A+B] } \\
\text { Cybrids } \\
\text { Untreated } \\
\# \text { vs } \\
\text { Treated } \\
\text { P value, } \\
\text { Fold }\end{array}$ & $\begin{array}{c}\text { D Cybrids } \\
\text { Untreate } \\
\text { d\# vs } \\
\text { Treated } \\
\text { P value, } \\
\text { Fold }\end{array}$ \\
\hline ALK & $\begin{array}{c}\text { Anaplastic } \\
\text { Lymphoma } \\
\text { Receptor } \\
\text { Tyrosine Kinase }\end{array}$ & NM_004304 & $\begin{array}{l}\text { Receptor tyrosine } \\
\text { kinase that plays an } \\
\text { important role in the } \\
\text { development of the } \\
\text { brain. Found to be } \\
\text { rearranged, mutated, } \\
\text { or amplified in a series } \\
\text { of tumors resulting in } \\
\text { many types of cancers. }\end{array}$ & $\begin{array}{c}<0.0001 * * * * \\
0.188 \pm \\
0.0973\end{array}$ & $\begin{array}{c}0.0001 * * * \\
, \\
0.175 \pm \\
0.0950\end{array}$ & $\begin{array}{c}0.290 \\
2.82 \pm \\
1.48\end{array}$ \\
\hline BRCA1 & $\begin{array}{l}\text { DNA Repair } \\
\text { associated }\end{array}$ & NM_007294 & $\begin{array}{l}\text { Nuclear Phospho- } \\
\text { protein that acts as a } \\
\text { tumor suppressor by } \\
\text { maintaining genomic } \\
\text { stability. Involved in } \\
\text { transcription, DNA, } \\
\text { repair of double- } \\
\text { stranded breaks, } \\
\text { recombination. }\end{array}$ & $\begin{array}{c}0.356 \\
1.36 \pm 0.372\end{array}$ & $\begin{array}{l}0.294 \\
1.55 \pm \\
0.477\end{array}$ & $\begin{array}{c}0.158 \\
3.42 \pm \\
1.39\end{array}$ \\
\hline EGFR & $\begin{array}{c}\text { Epidermal } \\
\text { Growth Factor } \\
\text { Receptor }\end{array}$ & NM_005228 & $\begin{array}{l}\text { Triggers cell } \\
\text { proliferation when } \\
\text { bound to epidermal } \\
\text { growth factor. }\end{array}$ & $\begin{array}{c}0.301 \\
0.760 \pm 0.217\end{array}$ & $\begin{array}{c}0.0246^{*} \\
0.492 \pm \\
0.171\end{array}$ & $\begin{array}{l}0.218 \\
.602 \pm \\
0.273\end{array}$ \\
\hline $\begin{array}{c}\text { ERBB2/HE } \\
\text { R2 }\end{array}$ & $\begin{array}{c}\text { Erb-b2 } \\
\text { Receptor } \\
\text { Tyrosine Kinase } \\
2\end{array}$ & NM_004448 & $\begin{array}{l}\text { Members of epidermal } \\
\text { growth factor receptor } \\
\text { family of receptor } \\
\text { tyrosine kinases. } \\
\text { Stabilizes binding of } \\
\text { epidermal growth } \\
\text { factors to receptor. }\end{array}$ & $\begin{array}{c}0.839 \\
1.06 \pm 0.298\end{array}$ & $\begin{array}{c}0.379 \\
0.820 \pm \\
0.189\end{array}$ & $\begin{array}{c}0.325 \\
1.96 \pm \\
1.75\end{array}$ \\
\hline
\end{tabular}

1 